\title{
MSR Fuel Salt Qualification Methodology
}

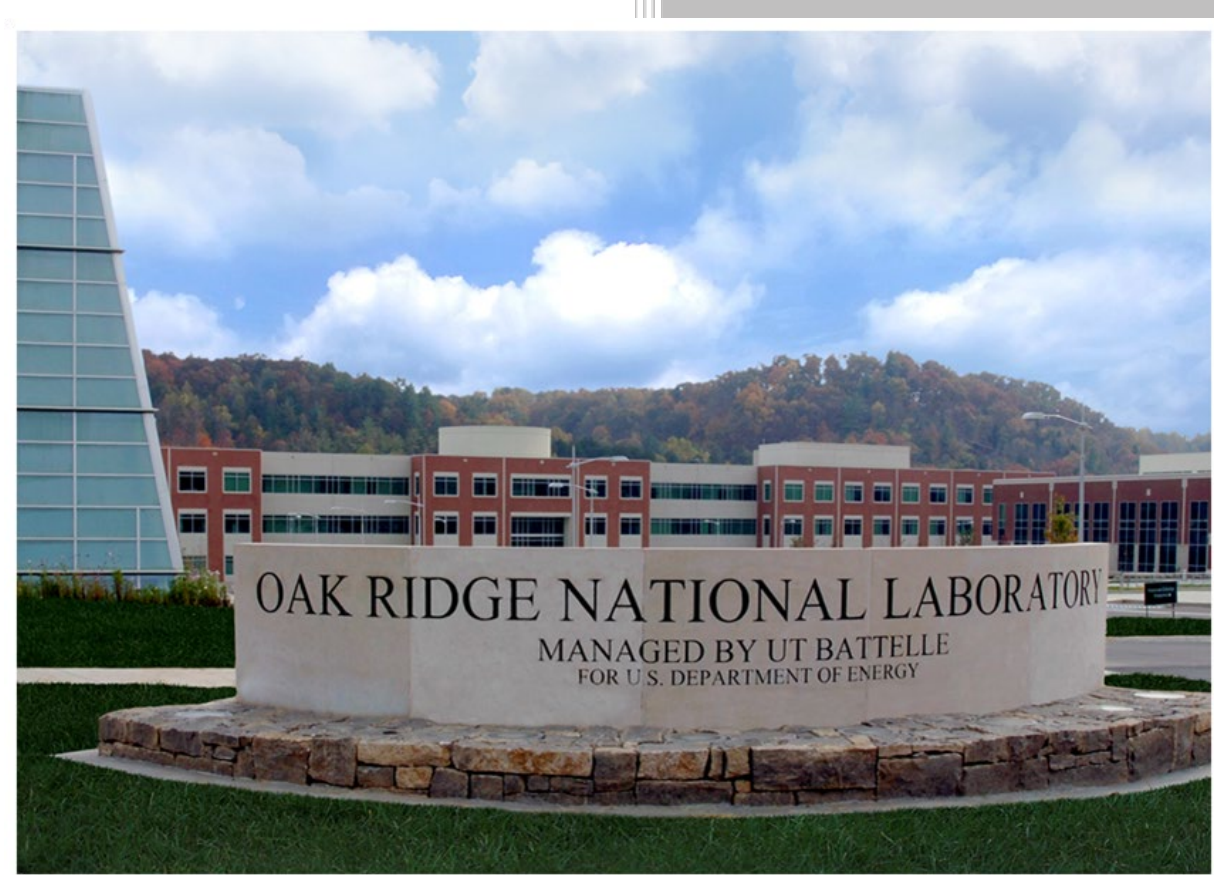

Approved for public release. Distribution is unlimited

D. E. Holcomb W.P. Poore, III

G. F. Flanagan

July 2020 


\title{
DOCUMENT AVAILABILITY
}

Reports produced after January 1, 1996, are generally available free via US Department of Energy (DOE) SciTech Connect.

Website www.osti.gov

Reports produced before January 1, 1996, may be purchased by members of the public from the following source:

\author{
National Technical Information Service \\ 5285 Port Royal Road \\ Springfield, VA 22161 \\ Telephone 703-605-6000 (1-800-553-6847) \\ TDD 703-487-4639 \\ Fax 703-605-6900 \\ E-mail info@ntis.gov \\ Website http://classic.ntis.gov/
}

Reports are available to DOE employees, DOE contractors, Energy Technology Data Exchange representatives, and International Nuclear Information System representatives from the following source:

Office of Scientific and Technical Information

PO Box 62

Oak Ridge, TN 37831

Telephone 865-576-8401

Fax 865-576-5728

E-mail reports@osti.gov

Website http://www.osti.gov/contact.html

This report was prepared as an account of work sponsored by an agency of the United States Government. Neither the United States Government nor any agency thereof, nor any of their employees, makes any warranty, express or implied, or assumes any legal liability or responsibility for the accuracy, completeness, or usefulness of any information, apparatus, product, or process disclosed, or represents that its use would not infringe privately owned rights. Reference herein to any specific commercial product, process, or service by trade name, trademark, manufacturer, or otherwise, does not necessarily constitute or imply its endorsement, recommendation, or favoring by the United States Government or any agency thereof. The views and opinions of authors expressed herein do not necessarily state or reflect those of the United States Government or any agency thereof. 
Reactor and Nuclear Systems Division

\title{
MSR FUEL SALT QUALIFICATION METHODOLOGY
}

\author{
D. E. Holcomb \\ W.P. Poore, III \\ G. F. Flanagan
}

July 2020

Prepared by OAK RIDGE NATIONAL LABORATORY

Oak Ridge, TN 37831-6283

managed by

UT-BATTELLE, LLC

for the

US DEPARTMENT OF ENERGY

under contract DE-AC05-00OR22725 



\section{CONTENTS}

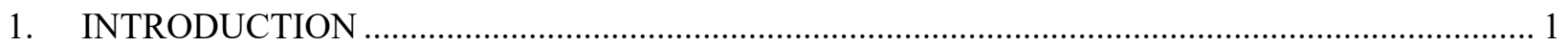

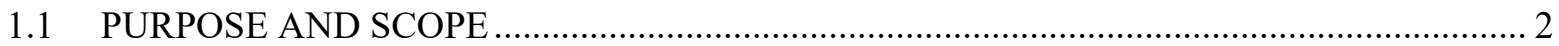

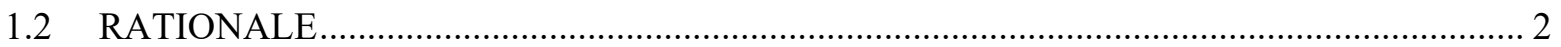

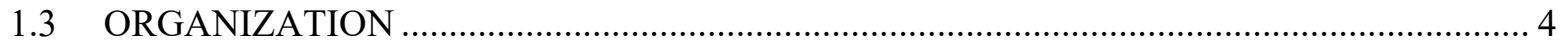

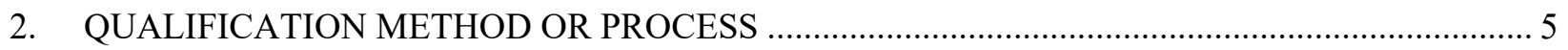

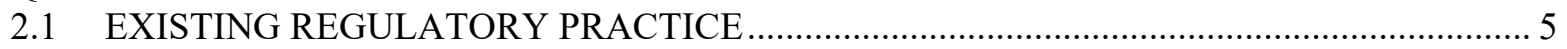

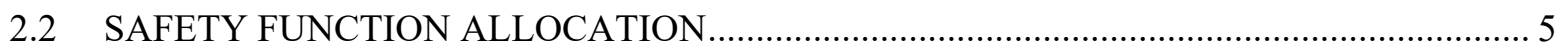

2.3 DEMONSTRATING ACHIEVEMENT OF FUEL SAFETY FUNCTIONS ......................... 5

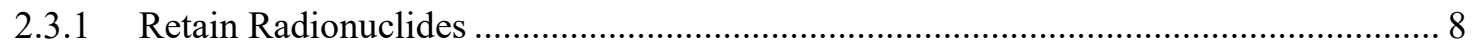

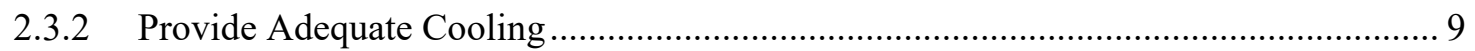

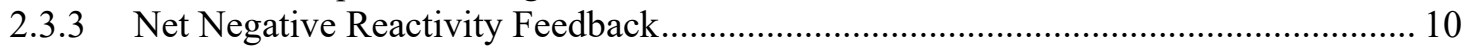

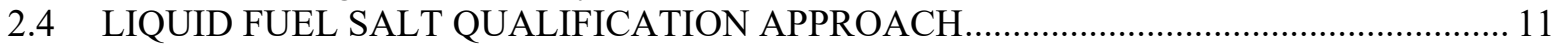

3. INFORMATION NEEDED TO SUPPORT MEASUREMENT-BASED FUEL

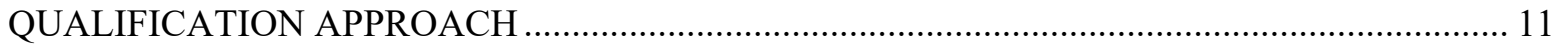

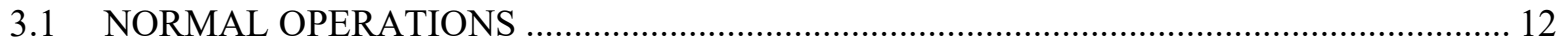

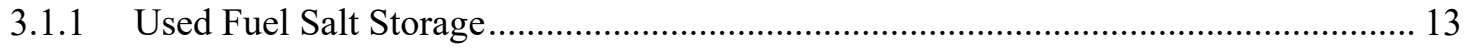

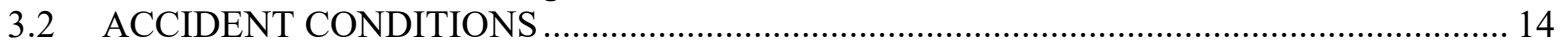

3.2.1 Fuel Salt-Related Accidents with the Potential for Radionuclide Release .................... 14

3.3 FUEL SALT PROPERTY INFORMATION NECESSARY TO SUPPORT A

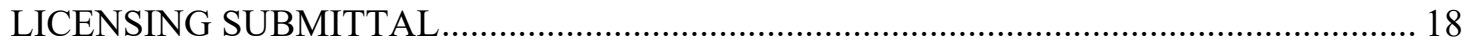

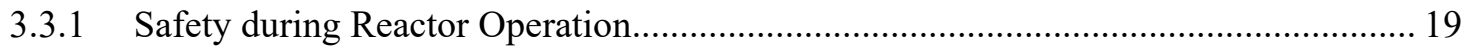

3.3.2 Safe Handling and Storage of MSR Fuel Salt Nuclear Materials - 10 CFR Parts

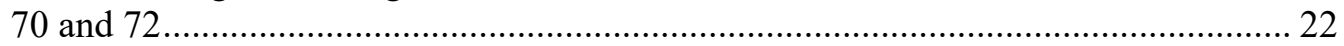

3.3.3 Material Control and Accountability - 10 CFR Part 74 …........................................ 23

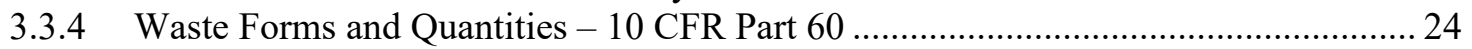

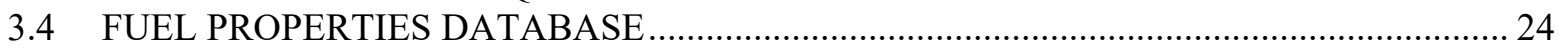

3.4.1 Simulation of Fuel Salt Properties Between Measurement Points.............................. 25

3.4.2 Evaluation of Safety Significance in Gaps in Fuel Property Data in Terms of

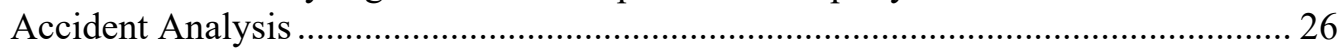

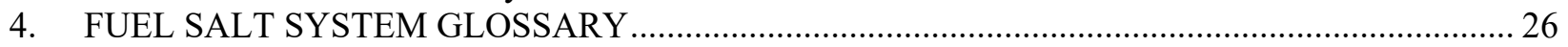

5. GUIDANCE NEEDED TO ADOPT AND IMPLEMENT NEW APPROACH.............................2 27

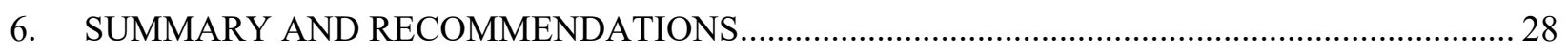

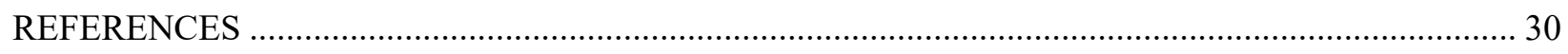

APPENDIX A. IDENTIFICATION OF REGULATORY GUIDANCE IMPACTING MSR FUEL

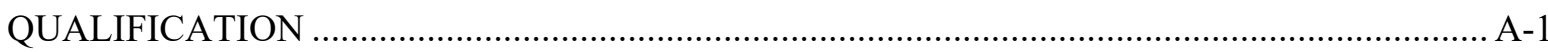




\section{INTRODUCTION}

This report documents the continuing activities at Oak Ridge National Laboratory (ORNL) in support of the US Nuclear Regulatory Commission (NRC) efforts to develop an efficient, appropriate process for liquid fuel salt system qualification. Fuel qualification for salt-cooled molten salt reactors (MSRs) is part of the ongoing coated particle fuel qualification effort [1].
Fuel qualification is a process which provides high confidence that physical and chemical behavior of fuel is sufficiently understood so that it can be adequately modeled for both normal and accident conditions, reflecting the role of the fuel design in the overall safety of the facility. Uncertainties are defined so that calculated fission product releases include the appropriate margins to ensure conservative calculation of radiological dose consequences [2].

The initial phase of ORNL's activities is documented in ORNL/LTR-2018/1045 Molten Salt Reactor Fuel Qualification Considerations and Challenges [3].

A key part of this effort is to establish the factors that should be evaluated or considered when qualifying an MSR fuel salt system. All prior qualification processes have logically subdivided the nuclear power plant into separately qualified subsystems. The subsystems are also collectively evaluated for safety performance. The recommended fuel salt system subdivision for MSRs is based upon the precedents established by other reactor classes, the distinctive safety functions of MSR fuel salt, and the NRC description of what constitutes fuel salt qualification (quoted above).

In a salt fueled MSR, the fuel salt has a dual function, as it contains the fissionable nuclei that constitute the nuclear fuel, and it also serves as the reactor coolant. The NRC full text glossary [4] describes nuclear fuel as "fissionable material that has been enriched to a composition that will support a self-sustaining fission chain reaction when used to fuel a nuclear reactor, thereby producing energy (usually in the form of heat or useful radiation) for use in other processes." The glossary also describes the reactor coolant system as "the system used to remove energy from the reactor core and transfer that energy either directly or indirectly to the steam turbine."

The extent of the reactor coolant pressure boundary for light water-cooled reactors (LWRs) is prescribed in 10 Code of Federal Regulations (CFR) 50.2 to include the components that are part of the reactor coolant system or that are connected to the system up to the outermost containment isolation valves. MSRs, however, are low-pressure systems, so their coolant boundary lacks a pressure retention function, but it does perform a radionuclide retention function analogous to fuel rod cladding. The cladding is also considered part of an LWR's fuel system. However, unlike solid fuel, and its cladding, the liquid fuel salt is separable and moves independently from its boundary materials under normal conditions. A proposed description of an MSR's reactor coolant boundary is provided in the glossary section of this report.

It is recommended that qualification of an MSR's fuel salt system should include all of the material containing fissionable elements or radionuclides that remain in hydraulic communication, but it should not include the surrounding systems, structures, or components (SSCs). In other words, fuel salt vapors and aerosols remain part of the fuel salt system until they become trapped adequately so that they would no longer have a reasonable method for returning to the bulk of the liquid salt or being releasable in the event of a reactor coolant boundary rupture. Similarly, the safety impacts of plated out materials on the reactor coolant boundary will be considered as part of fuel salt qualification, as the materials can be redissolved or resuspended in the bulk of the fuel salt. However, it is recommended that the safety performance requirements of the pumps, vessels, piping, heat exchangers, etc., that provide the physical boundary of the fuel salt system should be considered separately from the fuel salt qualification process, 
apart from the corrosion products that become incorporated into the fuel salt. The fuel salt's qualified life spans the time that an NRC license is required for possession or use of the fuel salt at the plant. Consequently, the behavior of both fresh and used fuel salt in onsite storage until transferred to an independent storage facility (10 CFR Part 72) are within the scope of fuel salt system qualification.

\subsection{PURPOSE AND SCOPE}

The overall purpose of this project is to develop the technical basis for an efficient, appropriate methodology or process for qualification of a liquid salt fuel system. Prospective license applicants have indicated that attempting to apply the existing solid fuel qualification process to liquid salt fuel is challenging, and consequently, it results in greater uncertainty, expense, and delay due to the substantial differences in liquid salt fuel characteristics and safety function allocation. This report defines the extent of the liquid fuel salt system (in the introduction above), identifies the regulatory requirements associated with fuel qualification, and includes a discussion of the regulatory elements necessary to implement the envisioned alternative liquid salt fuel qualification methodology. The report also includes information on important salt parameters that should be obtained prior to a licensing application and those that may need to be monitored and/or controlled during operation and subsequent long-term shutdown and storage conditions.

The fuel salt safety function allocations employed in this report apply only to liquid fuel salt MSRs in which (1) the critical region - the core - is located within a reactor vessel, and (2) heat transfer from the fuel salt is performed using a heat exchanger located outside the critical region. While the safety function-based evaluation methods employed in the current effort are anticipated to be generally applicable to other MSR design variants, neither the implications of designs that involve direct contact of the fuel salt and an immiscible coolant in the core nor those that employ either static or flowing fuel salts within tubes to form a critical region are considered. While it is acknowledged that one of the prior operational MSRs, the Aircraft Reactor Experiment (ARE), employed fuel salt flowing through tubes located within moderator blocks, thin-wall fuel salt tubes in the core present additional potential issues with fuel salt system qualification that are beyond the scope of the current effort.

\subsection{RATIONALE}

All nuclear power plants must perform the same high-level safety functions (1) containment of radionuclides, (2) rejection of decay or residual heat to the environment, and (3) control of reactivity. The fuel system has a substantial role in each of these basic safety functions in both solid and liquid fueled reactors. However, the elements that comprise the fuel system and the allocation of the safety functions among these elements differs substantially between solid and liquid fueled reactors.

The safety functions of LWR solid fuel systems depend upon several components, including the water, fuel pellets, cladding, grid support plate, subassembly walls or cans, grid spacers, and the fission gas plenum. The safety functions of liquid salt fueled systems also depend upon the performance of multiple elements, including the liquid fuel salt, the fuel salt system boundary materials, any in-core moderator and support materials, and the cover gas management system boundary. The fuel safety functions are allocated among the components of each reactor type. For instance, the cladding, fission gas plenum, and fuel pellet all have major roles in fission product retention in solid fueled reactors. In solid fuel reactors, the fuel pellets and fission gas plenum are the major source of operational and decay heat that must be removed under both normal and accident conditions. Liquid fuel, in contrast, is both a source of heat and its primary transfer medium. The cladding, fuel, and water moderator collectively provide reactivity feedback in LWRs. The liquid fuel and moderator materials provide a safety equivalent net negative reactivity feedback in liquid fueled reactors. Thus, achievement of a safety function of the liquid fuel salt system involves materials whose properties are not included in the fuel salt qualification (the moderator) 
apart from any corrosion or erosion products that become incorporated into the fuel salt. This is similar to the manner in which the safety function of LWR fuel involves the water moderator, which is not included in solid fuel qualification. The difference in the nature of the liquid fuel system components and the roles the individual components play in the overall safety of the facility will impact the current policies, which are primarily based on solid LWR fuel systems.

The existing regulations for solid fueled reactors do not align with components of liquid fuel systems, making it difficult or impossible to map previous solid fuel qualification efforts onto MSR fuel. Existing regulations also do not provide guidance for distinctive MSR fuel safety performance requirements arising from its liquid state. For example, RG 1.206 Section C.1.4.2, "Fuel System Design," indicates that the fuel system's mechanical design should include, as a minimum, the following four aspects:

1. mechanical design limits, such as those for allowable stresses, deflection, cycling, and fatigue;

2. capacity for fuel fission gas inventory and pressure;

3. listing of material properties;

4. considerations for radiation damage, cladding collapse time, materials selection, and normal operational vibration.

The emphasis on the behavior of these components is based on the safety functions allocated to them in the overall fuel system and the role of its safety functions in the overall facility safety. Many of these requirements are also strongly related to the need to protect the fuel from extremely dynamic accidents such as a large break loss-of-coolant accident (LOCA), which is not a credible event in a low pressure MSR design.

Since liquids do not support mechanical strain over time, design issues such as mechanical cycling limits and capacity for fission gas retention requirements are not meaningful for MSR fuel salts. Fission gases have limited solubility in liquid fuel, and for the most part, they inherently bubble out from the fuel salt, which prevents significant fission gas retention. Moreover, as an ionic liquid, MSR fuel salts are largely immune from radiation damage. However, fission or corrosion products may build up in the fuel salt and will eventually alter the material properties enough to affect the fuel salt's ability to fulfill its safety performance requirements.

During operation, the liquid state of MSR fuel presents distinctive conceptual and qualification challenges. These challenges include, but are not limited to, the following:

- fuel salt chemistry continuously changing during operation, as local LWR solid fuel chemistry changes do not alter the coolant chemistry;

- fuel flowing within and outside the reactor core rather than remaining stationary within the core as with solid fuel LWRs;

- continuous power and temperature cycling as the fuel circulates; and

- the lack of discrete fuel elements comprised of fuel pellets in sealed cladding whose performance can be evaluated collectively.

Solid fuel performance models include detailed data on thermo-mechanical and radiation exposure history, which is key to understanding their current and future mechanical performance. However, an 
inherent characteristic of liquids is their lack of mechanical memory. This makes liquid fuel's performance dependent only on its current nuclear, chemical, and physical properties. In other words, the history-dependent effects of liquid fueled MSRs are limited to the solid structural components adjacent to the fuel system.

The advanced reactor design criteria (ARDC) in RG 1.232 (derived from 10 CFR Part 50, Appendix A) are fundamental in the development of principal design criteria (PDC) to assure that the underlying safety objectives are met. The difference in the elements of the fuel system and the allocation of safety functions among the elements substantially increases the difficulty and complexity of understanding how to comply with the ARDC. For example, several of the ARDCs involve the quality and performance of the reactor coolant boundary. The Staff Requirements Memorandum (SRM) to SECY-18-0096, Functional Containment Performance Criteria for Non-Light-Water-Reactors, allows different approaches to fulfilling the safety function of limiting the release of radioactive materials. The SRM allows for a set of barriers which collectively function to effectively limit the transport of radioactive material to the environment. If a functional containment approach is taken, then allocating the safety performance requirements of the fuel system boundary among multiple containment layers may make it confusing to determine how the ARDC coolant boundary requirements should be applied. Also, the safety intent of some ARDCs may not be appropriate for liquid fueled MSRs. For example, ARDC 33 requires a reactor coolant inventory maintenance system as necessary. As the fuel salt is also the reactor coolant, ARDC 33 would appear to suggest that adding additional fuel salt (aka reactor coolant) under accident conditions could be an appropriate accident response, whereas a typical MSR safety response to a small break in the reactor coolant boundary would be to drain the coolant (aka fuel salt) out of the fuel salt circuit into a noncritical configuration drain system, thus shutting down the chain reaction and then cooling the drained fuel to limit further spread of contamination.

Interactions with stakeholders have indicated that the distinctive characteristics of MSRs lead to significant uncertainty and confusion about what information would be required in a license application. Consequently, a fuel qualification process tailored to an MSR's distinctive physical characteristics and safety performance requirements would improve the clarity, efficiency, and consistency of their regulatory process. Without regulatory guidance, future applicants will not have a clear understanding of what constitutes demonstration of reasonable assurance of adequate safety for liquid fuel.

\subsection{ORGANIZATION}

This report summarizes existing regulatory practice for solid fuel qualification, which is discussed in more detailed in the first phase project report [3]. Following this, the report compares the safety function allocation between solid and liquid fuels and then describes how solid fuel qualification enables demonstration of the fuel safety functions. An alternate, measurement-based approach for demonstrating equivalent liquid salt fuel safety characteristics is presented, followed by a description of the fuel salt thermophysical and thermochemical property data necessary to qualify liquid salt fuel using the proposed approach. The information needs are discussed in terms of preventing or mitigating generic MSR accidents with the potential for radionuclide release. The fuel salt property information necessary to support a licensing submittal including safety during operation, material control and accountability (MC\&A), and waste forms and quantities is then discussed. The role of a fuel salt property database in providing the required information is described, followed by a discussion of the data needed prior to operation to evaluate reactor safety with fresh fuel, as well as the measured data needed to assure continued safe operation. This is followed by a glossary of fuel salt system elements for MSRs: distinct fuel salt system definitions are needed to differentiate from LWR safety terminology (e.g., coolant pressure boundary), which does not map clearly to MSRs. The report then describes the regulatory guidance needed to enable the new liquid fuel salt qualification approach and provides a sketch of the content of a regulatory guide needed to implement the proposed qualification process. The report 
concludes with an appendix which identifies existing regulatory guidance related to MSR fuel qualification.

\section{QUALIFICATION METHOD OR PROCESS}

\subsection{EXISTING REGULATORY PRACTICE}

Fuel performance is a key element of LWR safety, so it has been studied extensively. However, no regulatory guide focuses on fuel qualification, so the fuel qualification process has been based on experience and manufacturing quality and operating performance data. For example, 10 CFR 50.46 (b)(1)(2)(3) [5] sets requirements on the fuel behavior during a LOCA event, which defines maximum cladding temperature, oxidation rate, release of combustible gases, and geometric stability. Lower level regulatory guidance is available for normal and anticipated operational occurrence (AOO) conditions. Section 4.2 of NUREG-0800 [6] defines expectations placed on LWR fuel under these conditions. Regulatory Guide 1.206 Section C.1.4, "Reactor" [7], provides the content of information needed to address the expectations found in NUREG-0800 Section 4.2.

Solid fuel systems of LWRs are made of several components, including fuel pellets, cladding, a grid support plate, subassembly walls or cans, grid spacers, guide tubes, thimbles, and the fission gas plenum. For qualification, the behavior of the fuel system is reviewed to ensure the design meets 10 CFR Part 50, Appendix A, General Design Criteria (GDC) 10 for normal and AOO conditions. In addition, the fuel failure mechanisms must be addressed during postulated accident conditions, including LOCA events. Mechanical effects, irradiation effects, and chemical effects such as oxidation, hydriding, and corrosion product buildup are considered when addressing potential LWR fuel rod failures. This information is generated from experimental data and fuel performance simulations.

The fuel qualification program must also address the fabrication, transportation, and storage of the fuel before and after use in the reactor, in addition to performance within core.

\subsection{SAFETY FUNCTION ALLOCATION}

Fuel safety functions are allocated among the components of each reactor type. In solid fueled reactors, the cladding, fission gas plenum, and fuel pellet/particle all have major roles in fission product retention. The fuel pellets and fission gas plenum in solid fuel reactors are the major source of operational and decay heat that must be removed under both normal and accident conditions. However, liquid fuel is both a source of heat and its primary transfer medium. The cladding, fuel, and liquid-moderator (if used) collectively provide reactivity feedback in solid fuel reactors, whereas the liquid fuel salt and solid moderator (if used) provide a safety equivalent net negative reactivity feedback in liquid fueled MSRs. Comparing the safety function allocation between solid fueled and liquid salt fueled reactors illustrates the differences between how the fuel forms support overall facility safety.

\subsection{DEMONSTRATING ACHIEVEMENT OF FUEL SAFETY FUNCTIONS}

Solid fuel has three safety functions. First, it retains radionuclides. Second, it maintains a coolable geometry, and third it must provide net negative prompt reactivity feedback. Solid fuel is typically evaluated at the rod level, as the cladding is an integral part of performing its safety functions. Gathering real-time fuel radiation damage / microstructure evolution data is not possible with solid fuels, and adequately predicting the condition and performance of solid fuel from first principles is beyond current modeling capabilities. Consequently, development of solid fuel qualification and performance models is based primarily upon a series of separate effects and integral tests, accompanied by long-term steady-state irradiation and post-irradiation examination (PIE), as well as thermo-mechanical testing and in-pile 
transient performance tests to simulate accident conditions. The data quality assurance (QA) requirements are expected to be governed by an approved QA program.

Predicting the performance of solid fuel is technically challenging due to the following factors

1. Complex set of microstructure-dependent radiation damage effects such as swelling and embrittlement,

2. Rate of exposure change dependence of material properties such as pellet-clad interaction for high ramp rates during power range operations,

3. Dependence of future performance on material history,

4. Core location dependence of the exposure conditions,

5. Geometry and scale dependence of radiation damage effects, and

6. Sequence and timing assumptions of accident response modeling.

Solid fuel qualification for fuel performance can be understood by constructing test fuel pellets/particles and rods, exposing them to normal and accident conditions, and subsequently examining their condition and radionuclide releases. Radiation damage of solid fuel has substantial microstructure (e.g., swelling, and cracking) and geometry (e.g., rod bowing) aspects, so test articles must be large enough to demonstrate safety-related phenomena. PIE is typically performed after several months of cooling and should be performed in hot cells due to high radiation doses from the fuel pieces. Post irradiation testing includes thermal and mechanical testing to simulate accident conditions, as well as correlation with unirradiated fuel thermo-mechanical performance. Solid fuel radiation damage is typically progressive and dependent on exposure condition, and there is a significant threshold before the damage can be observed. Consequently, lead test assemblies (LTAs) are irradiated to obtain longer term in-core, integrated fuel performance data. This enables prediction of fuel assembly-scale accident performance at the end of fuel lifetime, and it also addresses potential scaling issues for properties obtained on smaller samples in test reactors. Transient thermal and irradiation tests are also required, with both fresh and irradiated fuel to acquire data to enable modeling rapidly progressing accident scenarios. Data-driven models of solid fuel performance can then be developed and validated based upon the extensive exposure testing.

Liquid salt fuel also has three safety functions. First, it retains radionuclides; second, it is the heat transfer media for both operational and decay heat removal; and third, it must provide a net negative reactivity feedback during upset conditions. The relative importance of the safety functions varies with the location of the fuel salt. For example, fuel salt in a criticality safe drain tank still needs to retain radionuclides and serve as a heat transfer medium for decay heat removal, but it would no longer be required to provide a net negative reactivity feedback. The components of liquid salt fuel safety performance during operation are presented in Figure 1. Not all of the individual elements of liquid fuel salt system safety would be part of fuel salt qualification. For example, the thermal expansion of the reactor vessel changes the fuel salt geometry, which impacts overall reactivity feedback, but the expansion is not a fuel salt property. This section describes how salt properties and processes affect overall facility safety. 


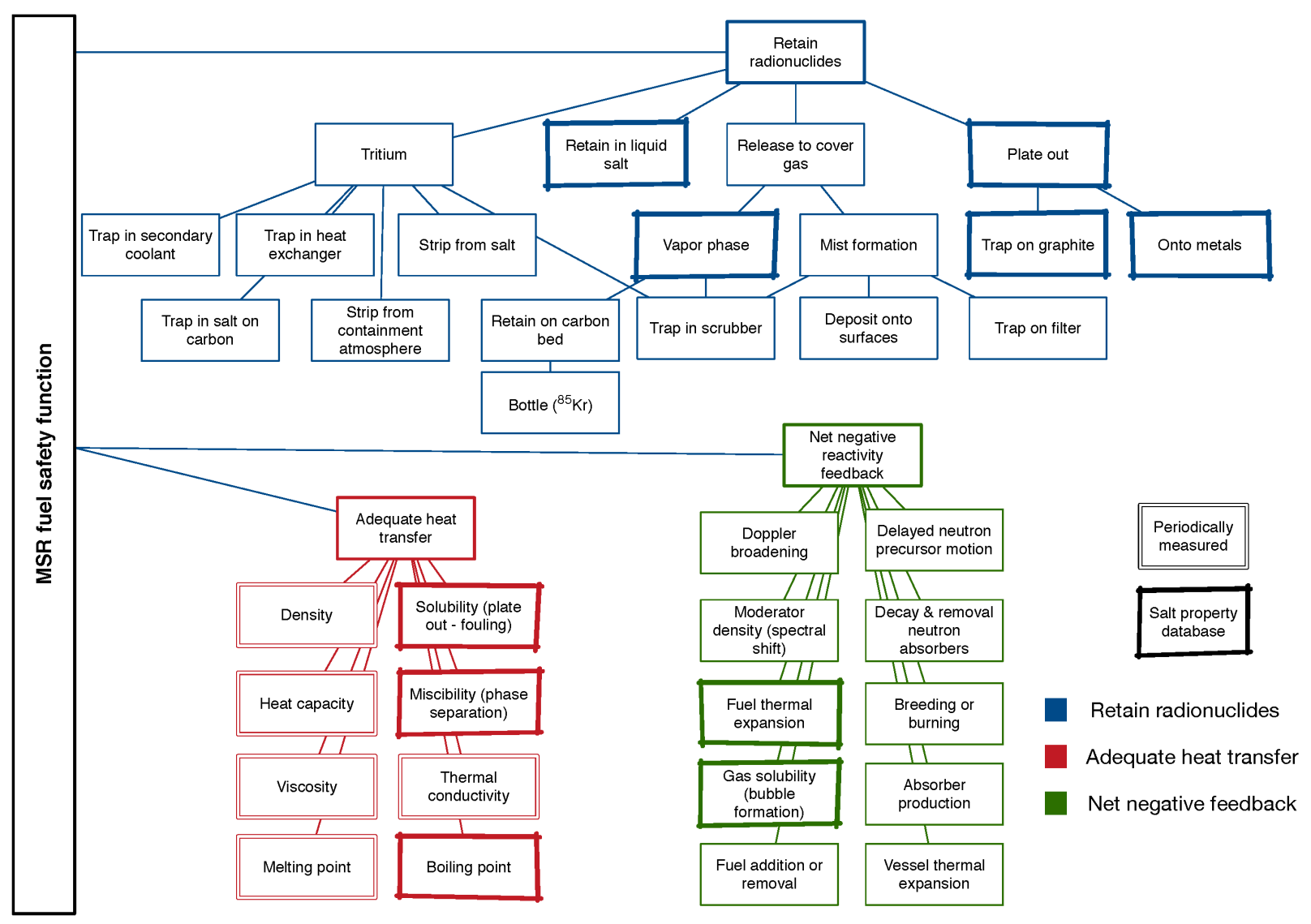

Figure 1. Components of MSR fuel salt safety performance during operation.

The properties of fuel salt will inherently change with operation due to the fission process, or they may change inadvertently due to contamination. Properties may also be purposefully changed due to refueling and chemistry adjustment. The extent to which the fuel salt boundary materials may contaminate the fuel salt, altering its thermochemical or thermophysical properties, will be an element of fuel salt qualification. The ability to adjust fuel salt composition and properties in real time is a key difference from solid fuel. The thermophysical and thermochemical properties of fuel salt are functions of temperature and composition. The temperature of the fuel salt varies along the fuel salt circuit under both normal and accident conditions. Having an adequate database of fuel salt property variance with temperature and composition is central to being able to rely on periodic salt composition measurement to assess the current fuel salt safety performance capability.

Liquid fuel salt, which consists largely of positive and negative ions, has no long-range structure and is continuously mixed as it flows through its circuit. Consequently, representative data can be obtained from small samples. Liquid fuel salts have been shown [8] to be immune from radiation damage, apart from transmutation, because the kinetics and thermodynamics of the ionic compounds that comprise liquid salts ensure rapid recombination of these compounds following radiolysis. That is, while radiation may break chemical bonds in ionic liquids, those bonds would almost instantaneously reform. Measuring properties of fuel salt samples provides a near real-time, direct update of the physical and chemical status of the fuel salt within the circuit.

The types of challenges to safety functions in liquid salt-fueled MSRs under accident conditions also differs from those in LWRs. In LWRs, it is possible to subject the fuel to rapid and highly energetic 
transients that do not exist in liquid salt-fueled MSRs. For example, when considering AOO performance requirements, liquid salt-fueled MSRs do not have an analog to departure from nucleate boiling, pelletclad interaction, and fuel centerline melting caused by reactivity transients. Furthermore, when considering design-basis accidents (DBAs), due to its low operating pressure and high boiling point, liquid salt fuel cannot be subjected to the highly energetic mechanical and thermal stresses resulting from a large break LOCA, which is a significant challenge to LWR fuel safety performance. Consequently, fuel qualification for liquid salt-fueled MSRs is better demonstrated by maintaining fuel chemistry within a predetermined set of bounding values, providing reasonable assurance that the fuel safety functions are maintained. The bounding values for the salt properties are those that assure adequate safety under both normal and accident conditions. The required set of values will be determined by performing accident progression analysis.

\subsubsection{Retain Radionuclides}

The safety case for the fuel salt system is an element of the overall reactor safety case. Liquid salt, which is unlike clad fuel rods but is like tristructural isotropic (TRISO) fuel, in which Ag, Cs, Sr, and $\mathrm{Kr}$ diffuse out of the intact fuel to some degree under normal operating conditions [9]. Liquid salt is not intended to retain all radionuclides during normal operation. The amounts and forms of radionuclide release from fuel salt will be key inputs to the overall reactor radionuclide release safety case. Fuel salt qualification requires development of sufficient understanding of the physical and chemical behavior of the fuel salt to ensure it performs adequately under normal, AOO, DBA, and beyond design-basis accident (BDBA) conditions. The radionuclide retention provided by additional nonfuel salt containment layers or barriers is also an important but separate aspect of overall MSR safety during both normal and accident conditions.

The boiling points of fuel salts are well above MSR operating and accident conditions, so the salt vapor pressure in the cover gas system will be much less than one atmosphere. The noble gases have low solubility in liquid salt and will largely bubble out of the salt, whereas nonsoluble (noble) solid elements will either plate out onto salt wetted surfaces, be filtered out, or evolve into the cover gas as a mist. The radioactive portion of the emerging noble gases and volatile fission products will continue to decay after leaving the salt. A significant fraction of the ${ }^{137} \mathrm{Cs}$ fission product - which constitutes a considerable portion of the fission product activity for the first few years-results from ${ }^{137} \mathrm{Xe}$ decay systems. These systems remove the ${ }^{137} \mathrm{Xe}$ from the fuel salt, thus shifting the location of this source term from the core to the waste stream. The cover gas system must provide low-leakage containment, decay heat removal, and storage volume for the evolving radionuclides. The low-leakage containment layer must be sufficiently robust to contain any combination of mist, particles, vapor, and noble gases to avoid being dependent on detailed mist / particle / vapor / noble gas composition information. The low-leakage containment layer must also be designed to avoid plugging due to vapor and mist solidification or particle deposition. The radionuclide retention function of the cover gas system boundary must be evaluated separately from the fuel salt properties.

Tritium will be a transmutation product in liquid salts that contain lithium or beryllium. Smaller amounts of tritium will also be generated as a ternary fission product and by higher energy neutron interaction with fluorine. Tritium has low solubility in fuel salt, so it will largely either diffuse out through the structural materials, or it will be captured in carbonaceous materials in contact with the salt. Tritium retention must be included in the qualification of the fuel salt boundary layers, but only to the extent that its retention in the fuel salt is credited in the reactor safety case. 


\subsubsection{Provide Adequate Cooling}

Fuel salt is an isotropic Newtonian fluid. Its heat transfer properties result from its thermophysical characteristics. The chemical and physical properties of materials are almost entirely determined by their elemental composition, independent of the isotopic composition of the elements. Achieving adequate heat transfer is based on maintaining fuel salt thermophysical properties within acceptable ranges. Fuel salt has a number of thermochemical and thermophysical properties that must be maintained within acceptable limits for the salt to provide acceptable heat transfer. It is important to understand the physical and chemical behavior over the range of potential fuel salt compositions and temperatures in order to avoid and/or mitigate accidents related to inadequate cooling of fuel salt.

The thermochemical and thermophysical properties of fuel salts are fully described by their chemical composition and temperature. Consequently, the fuel salt thermophysical property database can be generated using small samples of low or no-radioactivity materials. ${ }^{*}$ Fundamentally, fuel salt composition and temperature measurement are the only data needed to fully specify fuel salt thermophysical and thermochemical properties. However, at the current level of scientific understanding, the salt's thermophysical and thermochemical properties should be measured and correlated with fuel salt composition and temperature to develop an empirical database of fuel salt properties. Measurements of fuel salt thermophysical properties at operating reactors would be continually added to the fuel salt properties database.

As fission, corrosion, contamination, and transmutation products build up in the salt over time, they can result in an immiscible phase with a higher melting temperature or fissile material concentration than the remainder of the fuel salt, potentially plugging the fuel salt circuit or producing a reactivity transient. The fuel salt can also be vulnerable to freezing (1) before adequate amounts of fission products have been built-in to provide self-heating, (2) due to mis-operation of the secondary heat transfer loop, or (3) during long shutdown periods in which self heating is significantly reduced. Measuring the fuel salt's composition and correlating it with the fuel salt's thermophysical properties provides assurance that an adequate margin is maintained from salt freezing, phase separation, and/or plate out.

Material solubility increases with temperature. Some MSR designers plan to employ fuel salt with the maximum possible fissile material content. High fissile content salts can be vulnerable to plating out fissile material in the lower temperature section of the fuel circuit, restricting flow and potentially resulting in criticality outside the core. Plating out of nonfissile, insoluble materials could result in fouling the heat transfer surfaces. Insoluble materials could alternatively build up into suspended particles that increase the salt's erosiveness. While heat transfer performance would be continuously monitored as part of plant operations, measuring fuel salt composition will provide insight into the salt's insoluble material loading, as well as guidance for cleaning and filtering. Similarly, the fuel salt oxidation state is strongly correlated with its corrosiveness. Measuring the salt's redox condition and/or the change in its corrosion product loading provides assurance that the fuel salt is not significantly corroding the fuel salt circuit.

Fuel salt viscosity, density, thermal conductivity, and heat capacity are heat transfer parameters that vary with temperature and salt composition. Heat transfer with any Newtonian fluid can be modeled with reasonable accuracy in MSR-relevant conditions using fluid viscosity, density, and heat capacity. Thermal conductivity and optical properties will impact the heat transfer in specialized situations. For example, liquid phase thermal conductivity will become an important heat transfer parameter in stagnant conditions in which convective cells cannot be established, such as in salt that has permeated into graphite pores or within compact heat exchanger channels. Liquid phase thermal conductivity may also be important during

\footnotetext{
${ }^{*}$ The intensely radioactive transplutonium elements will constitute a small enough fraction of the fuel salt as to not significantly alter its thermochemical or thermophysical properties.
} 
start-up of natural circulation heat decay heat removal systems, especially in designs that require flow reversal. Measurement of the key thermophysical heat transfer properties can provide data to map the fuel salt current condition to a fuel salt property database. Measurements of fuel salt composition and temperature during reactor operation can then provide the heat transfer parameters via the database.

\subsubsection{Net Negative Reactivity Feedback}

GDC 11 requires that fuel provides a net negative reactivity feedback for power range transients. MSRs operate with little if any excess reactivity beyond what is useful for power maneuvering. Liquid-cooled solid fueled reactors must avoid the power excursion associated with large positive reactivity insertions due to their potential to damage the fuel and release radionuclides, as well as the potential for loss of heat transfer capabilities upon departure from nucleate boiling. The critical damage phenomena resulting from unsafe positive reactivity feedback for an MSR would be damage to the fuel circuit boundary either from overheating, or propagation of a density/pressure wave resulting from intense local energy deposition. Both of these phenomena are mitigated by the low-pressure, free surface of the fuel salt circuit, providing MSRs a longer time margin to provide an overall net negative reactivity feedback.

Fuel salt provides reactivity feedback through multiple mechanisms.

1. Changing temperature (changing neutron absorption probability while slowing down - aka Doppler broadening);

2. Changing the fuel salt density, as well as heating the solid moderator, which decreases its density, thereby shifting the neutron spectrum and the amount of fissile material in core at the speed of sound;

3. Bubble formation (noble gases, volatile fission products) and transport (pump entrained cover gas bubbles) both into and out of core, changing effective speed of sound and density;

4. Movement of delayed neutron precursor atoms both out and into the core;

5. Breeding and/or burning out of fissile materials;

6. Production of parasitic absorber materials;

7. Physical removal of absorber materials, especially noble gases;

8. Decay and/or transmutation of absorber materials, including Xe decay; and

9. Heating (thermal expansion) of the reactor vessel changing the leakage and the amount of fissile material in the critical region.

The reactivity feedback mechanisms are of different magnitudes and have different time constants. For most fuel salts, Doppler broadening provides adequate strong prompt negative reactivity feedback. However, the fuel salt density change would also be rapid enough to mitigate fuel circuit boundary damage. ARDC 11 (NRC RG 1.232) requires that the net effect of the prompt inherent nuclear feedback characteristics tends to compensate for a rapid increase in reactivity. For MSRs, the term prompt in ARDC 11 would need to include all of the reactivity feedback mechanisms that act sufficiently rapidly to avoid fuel circuit boundary damage. The capability to provide net negative reactivity feedback can be confirmed by updating the reactor physics models to reflect the measured fuel salt composition. 


\subsection{LIQUID FUEL SALT QUALIFICATION APPROACH}

A measurements-based approach to developing adequate understanding of the physical and chemical behavior of fuel salt has two measurement aspects. Prior to operation, a fuel salt property database is empirically generated, providing a mapping of fuel composition and temperature to thermochemical and thermophysical properties. The database must be of adequate fidelity to enable mapping the acceptable boundaries of the fuel safety-related properties. The bounding properties database provides confidence that no safety-related fuel salt properties would be reasonably anticipated to exceed their acceptable limits as specified in the plant's technical specifications prior to their next measurements. Since the salt properties do not depend on the isotopic composition of the salt, the database can be constructed using minimally radioactive (for those elements that do not have non-radioactive isotopes) or non-radioactive isotopes of the elements comprising the fuel salts. As the fuel salt properties change over timeinherently due to the fission process, inadvertently due to contamination, and purposefully due to refueling and chemistry adjustment - measurements will be performed periodically to confirm that the safety-related fuel salt properties remain within acceptable limits. Fission produces both insoluble elements and noble gases. These materials will initially be suspended in the fuel salt until either depositing on a surface or escaping at a free surface. If they are not separated or filtered adequately, then the fission gas bubbles and suspended particulates can build up sufficiently to impact reactor performance.

The fuel salt database will initially include fuel salt property measurements, along with models for interpolating between measured points. The number of possible minor elements and compositional variations makes developing a densely populated fuel salt properties database prior to operation technically difficult. Consequently, both fuel salt composition and property measurements should be made early on during operation to ensure that the fuel salt properties remain within acceptable limits and to further populate the database over time. The properties of ionic liquids vary continuously with small changes in composition. Therefore, the database would initially need to be populated sufficiently so that reactor performance is adequate at measured points covering the measured salt composition within the uncertainty bounds in the property interpolation model. The isotopic composition measurements, which are used to determine decay heat production, potential source term, and reactivity feedback, must be performed directly on the fuel salt samples. Fuel salt thermophysical and thermochemical property measurements, however, can continue to be made using minimally radioactive mimic fuel salt as they do not depend on the isotopic composition. A central purpose of the fuel salt properties database is to progress to a point that only periodic salt composition measurement is required and to employ the database to determine resulting thermophysical and thermochemical properties.

\section{INFORMATION NEEDED TO SUPPORT MEASUREMENT-BASED FUEL QUALIFICATION APPROACH}

Fuel qualification requires an adequate understanding of fuel properties so that their role may be reflected in overall plant safety performance under normal and accident conditions (AOO, DBA, BDBA, or design extension conditions [DECs]). Consequently, liquid fuel salt properties must be known well enough to provide the information necessary to demonstrate adequate achievement of the overall plant safety objectives. Knowledge of the fuel properties must be sufficient to assess their contribution to any event sequence that could result in dose to a member of the public beyond that specified in 10 CFR 20.1301 or dose to a worker beyond that specified in 10 CFR 20.1201. Additionally, adequate fuel salt property information must be available to assess the role of the fuel salt in compliance with non-reactor operation safety requirements, as well as MC\&A and waste form and quantity regulations. Providing reasonable assurance that the roles of the fuel salt have been accounted for in the achievement of the plant safety 
objectives is accomplished through modeling the fuel salt's role in plant safety performance under both normal and accident conditions.

Liquid fuel salt performance requirements will depend on the accident sequences, fuel composition, radionuclide release characteristics, and barriers of each particular reactor design. However, the common characteristics of liquid halide fuel salts enable development of high-level, generic fuel salt property information requirements that would apply to any MSR. MSRs, however, represent such a diverse set of design options that alternate measurements may be required for some configurations. Some MSR designs call for the fuel salt to be located in tubes within the core, where the tubes are cooled by another coolant fluid. In some designs, the fuel salt tubes are vented to avoid fission gas pressure build up. Others connect the tubes to an upper and lower plenum and circulate the fuel salt more slowly to allow for chemistry control, fission gas removal, and refueling. MSRs in which the fuel salt is located in vented tubes within the core do not afford access to the salt during operation for composition measurement and cannot be as easily refueled online, thus requiring a larger reactivity margin. The need for additional offline fuel property measurements is a significant part of the rationale for excluding these designs from the proposed measurement-based qualification method.

Molten Salt Reactor Experiment (MSRE) experience provides limited information on which fuel salt properties would be necessary to measure at future MSRs. MSRE did not operate its fuel salt to high burnup and did not need to measure changes in thermophysical properties. While the salt composition was periodically measured and measurement techniques were developed as part of the overall MSR science and technology program, the only parameter measured for reactor operations was the concentration of chromium in the fuel salt [10]. Uranium concentration, while measured chemically, was much more sensitively determined by its impact on reactivity [11]. The chromium concentration was used as a surrogate for overall salt corrosivity. Redox adjustment was made to the fuel salt by contacting the fuel salt with beryllium metal if the chromium concentration increased between samples. The primary operational finding derived from the measurement was that a small amount of oxygen was introduced into the system each time it was opened.

\subsection{NORMAL OPERATIONS}

Measurement-based fuel salt qualification provides the information necessary to ensure that the fuel salt will continue to perform its safety functions. During normal operations, the fuel salt serves as the fuel, and it also generates heat and serves as a heat transfer medium. Many of the fission products are produced and retained in the fuel salt. Others evolve out into the cover gas, or plate onto the salt-wetted surfaces. The salt becomes more oxidative in use as more fissions occur. The fuel salt is maintained in a reducing state by adding a redox control agent which may be incorporated into the fissile or fertile material addition. Criticality is maintained by adding fissile or fertile material to the salt and removing mixed fuel salt as necessary to maintain the intended fuel salt inventory.

MSRs will operate with low excess reactivity. Net negative reactivity feedback would initially be predicted with reactor physics models based upon the prescribed fuel salt composition and properties. Reactor physics measurements will be made during initial startup and acceptance testing to confirm the predictions. As the fuel salt composition evolves with use, the reactor physics models will be updated based upon both predictions and measurements of the fuel salt composition and reactor power history. Due to the continuously changing fuel composition, continuing reactor physics measurements will help maintain reasonable assurance that the MSR has net negative reactivity feedback. Online reactor physics measurements are based upon monitoring the reactor's response to small, controlled amounts of reactivity changes. Reactor stability testing is important for MSRs because of the changing fuel salt composition and the difficulty of continuously monitoring the composition and distribution of short-lived fission products, including delayed neutron precursors. A typical means of demonstrating reactor stability is to 
provide a small reactivity oscillation and to monitor the resultant reactor power response (i.e., through frequency response testing) [12]. The frequency of reactor stability testing required will depend on reactor design and operation. For example, fast spectrum reactors would have a smaller delayed neutron fraction but would be less impacted by fission product (notably xenon) removal.

Fuel salt under normal operating conditions is a Newtonian fluid (neglecting the effects of bubbles and suspended particulates), and its capability to transfer heat depends upon its heat capacity, density, and viscosity, all of which are functions of temperature and composition.

Fuel salt will retain some of the fission products, and others will evolve out into the cover gas or plate onto the salt-wetted structures. Knowing the fuel salt solubility limits and the component material vapor pressures as a function of temperature will be necessary in order to model the evolution of the fuel salt's radionuclide retention. This information would serve as the starting point for a radionuclide release calculation in the event of an accident.

Fuel salts are vulnerable to becoming much more corrosive during operation. This can occur relatively rapidly through contamination, or progressively due to improper chemistry control. Highly corrosive fuel salt would degrade one of the reactor's safety functions (retain radionuclides). Demonstrating that the fuel salt has not become significantly more corrosive will be an important element for maintaining fuel salt qualification. A primary means for any halide salt's corrosivity to increase would be through becoming more oxidizing, so directly measuring the fuel salt redox would be desirable. At the MSRE, an indirect redox measurement technique was employed; the change in the concentration of the most oxidizable component of the container alloy was tracked via periodic sampling / composition measurement. While the measurement of redox was indirect, measuring the amount of corrosion product added to the fuel salt directly represented the key safety consequence of redox changes: increased corrosion. However, monitoring corrosion product build-up in the fuel salt quantifies overall corrosion. Additional local monitoring of corrosion may be necessary in locations anticipated to have higher corrosion rates, such as at the hottest portion of the fuel salt loop, or where a flow stream impinges on a surface.

Ensuring that the fuel salt continues to be capable of performing its safety functions can be accomplished by measuring its isotopic composition, heat transfer properties, and redox condition. The fuel salt isotopic composition and validated reactor physics models can both be used to demonstrate maintenance of negative reactivity feedback, and direct measurement of the reactivity feedback response would provide additional confidence. The required frequency and the allowed uncertainty in the measurements will be design dependent. The required measurement frequency will depend on how quickly the property value changes and the extent to which the changes affect safety performance. Fuel salt reactivity would be expected to require frequent small adjustments, just as the boron dilution is adjusted or rods are withdrawn to compensate for burnup in LWRs. In contrast, salt viscosity varies little with changing salt composition, so it may only require measurement every few years. The rate of property change will vary with the power density of the salt and the fission product cleanup strategy. The MSRE had a fuel salt power density of $\sim 15 \mathrm{MW} / \mathrm{m}^{3}$, whereas fast-spectrum MSRs may have power densities of $300 \mathrm{MW} / \mathrm{m}^{3}$. The same properties will also require assessment, albeit over a wider temperature range, so that the safety performance of the salt can be modeled under accident conditions.

\subsubsection{Used Fuel Salt Storage}

Used fuel at MSRs comprises both spent fuel (fuel that has been used to the extent that it can no longer sustain a chain reaction) and fuel that is being stored for reuse (i.e., additional fuel produced by breeder reactors, or fuel intended to be returned to service in a replacement fuel salt circuit). Used fuel salt storage will be part of normal operations for designs that remove fuel salt from the primary loop onsite. The fuel salt will initially be liquid, but it will solidify as its heat generation rate drops. Used fuel salt will continue 
to contribute to only slightly modified fundamental safety functions, avoiding criticality while providing adequate cooling and preventing radionuclide escape. Used MSR fuel will be stored in tanks with favorable geometry and sufficient neutron absorption to remain subcritical. Used thermal spectrum MSR fuel requires a heterogeneous configuration with neutron moderation to achieve criticality. Used fastspectrum MSR fuel will contain larger amounts of fissile material and would be vulnerable to unintended criticality if enough neutron moderation is provided. The requirements provided in 10 CFR 50.68 on maximum allowable k-effective and confidence levels for used fuel storage are directly applicable to used fuel salt.

Adequate passive decay heat rejection must be provided to avoid damaging the used fuel salt container (which will likely be made of stainless steel) from thermally induced deformation. Natural circulation of used fuel salt within the storage container will decrease the temperature differences within the fuel salt container. The internal pressure of the fuel salt container will only increase significantly if the fuel salt temperature increases to its boiling point. Fuel salt boiling points are well above the softening temperatures of reasonable container materials, so fuel salt temperature will likely be the limiting container stressor. Once the fuel salt has solidified, it will be suitable for transfer to independent storage and thus will become subject to the requirements of 10 CFR Part 72 (see Section 3.3.2).

\subsection{ACCIDENT CONDITIONS}

In order to cause dose to the public, fuel salt radionuclides would need to leak past or cause failure of their containment systems. MSR containment leakage characteristics and fuel salt properties that could cause failure of the plant's containment are thus central to modeling the fuel salt's role in achieving the overall plant safety objectives. Note that tritium release through intact containment structures also must be included in the evaluation. 10 CFR Part 50, Appendix J, provides the containment leakage testing requirements for LWRs and includes the statement: "These test requirements may also be used for guidance in establishing appropriate containment leakage test requirements in technical specifications or associated bases for other types of nuclear power reactors." The Appendix J requirements are parameterized in terms of the peak design basis accident containment pressure, so they are largely independent of reactor class. One of the challenges in appropriately applying Appendix $\mathrm{J}$ requirements to MSRs is using the term primary reactor containment for a system that employs segmented, layered (i.e., functional) containment.

\subsubsection{Fuel Salt-Related Accidents with the Potential for Radionuclide Release}

Fuel salt qualification requires developing an adequate understanding of the fuel salt's behavior so that it can be adequately modeled for both normal and accident conditions, thus reflecting the role of the fuel design in the overall safety of the facility. Retaining radionuclides within containment is a fundamental element of facility safety. For radionuclides to be released into the environment, multiple layers of essentially leak-tight radionuclide barriers would need to be breached or bypassed. In order to qualify fuel salt, adequate knowledge must be available to model the role of the fuel salt in initiating a breach or bypass of any containment layer, as well as the salt's continuing capability to retain radionuclides. Mechanistic models of the chemical and physical interactions of the fuel salt - both directly with the containment materials and indirectly with other materials within containment under accident conditionsare central to developing potential accident source terms.

Identifying the set of accidents that could challenge the radionuclide retention fundamental safety function is based on the inherent characteristics of fuel salt, the low system pressure, and a conceptual model for exterior containment layer(s). Exterior containment layer(s) must be subjected to a stressor to fail. Both the ARE and MSRE designers performed safety evaluations of their designs [13, 14]. These prior safety evaluations resulted in credible accident scenarios in which pressure was the principal 
mechanism to cause radionuclides to escape from the plant. The physical separation of the inner and outer containment layers in both of these designs, combined with low system pressure, prevented substantial direct chemical or mechanical interaction between the fuel salt and the outer containment layer. MSR designs that do not include substantial separation between inner and outer containment layer(s) could have credible additional mechanisms such as thermal shock, direct heating, or chemical attack to stress exterior containment layer(s). Also, in any MSR design, a massive rupture of the innermost containment layer could result in the fuel salt pouring out onto the bottom of the next containment layer, which could result in thermal shock and/or chemical corrosion. Consequently, all known MSR designs include features such as stainless steel catch pans / guard vessels to mitigate the consequences of fuel salt rupture accidents.

For MSR designs that lack credible mechanisms for significant direct fuel salt interaction with the exterior containment layer, three internal accidents related to fuel salt property have been identified with the potential to release radionuclides through multiple layers of containment:

1. Pressurizing exterior containment layer(s) to failure due to leaks or ruptures in inner containment layers (i.e., a fuel salt boundary)

2. Pressurizing exterior containment layer(s) to failure and/or thermally failing exterior containment layer(s) through lack of adequate decay heat removal

3. Pressurizing exterior containment layer(s) to failure through unintended criticality outside of the core region

Tritium leaking through intact containment layers is primarily a normal, high-temperature operations issue. Exterior containment layers would not be at high temperature during normal operations, so they would retain tritium.

The following subsections describe the impact of fuel salt properties on the progression of each of these accidents in sequence. The accident progression discussion provides some description of MSR design characteristics to show the variation (if any) in the amount of required fuel salt property information for different plant design options. For example, more information about the surface temperature of leaking fuel salt would be necessary for MSR designs without an inert containment environment and combustible materials within containment due to the potential for the fuel salt to serve as an ignition source.

\subsubsection{Fuel salt boundary leaks or ruptures}

Low pressure is a key feature for radionuclide retention within MSR containment barrier layers. All MSRs will maintain their containment layers at low pressure during normal operations. As an example, the MSRE operated with a slightly negative containment pressure so that leakage would be inward during normal operation. The plant design and specific accident scenario will determine the mechanisms by which containment pressure could increase in the event of an inner containment layer failure.

1. Fission gases or radionuclide vapors could be released into the containment through a breach in the cover gas system;

2. The fuel salt boundary could rupture (large break LOCA), releasing the fuel salt into containment, heating the containment atmosphere, and thereby increasing its pressure;

3. A component for structural cooling or lubricant fluids within containment could be heated by leaking fuel salt and could possibly ignite or change phase, resulting in pressurization; 
4. Leaking fuel salt could flow onto insulation or concrete, resulting in vapor-generating chemical reactions; or

5. The power cycle fluid could be released into containment through ruptures in both the primary and secondary heat exchangers or secondary piping.

An accident would need to cause sufficient pressurization to rupture or permeate through a containment layer to be relevant to fuel qualification. Fission gas and fuel salt vapor release from normal operating temperature salt would only minimally impact the pressure of the much larger surrounding containment volume. While knowledge of the particular species of radionuclide vapor releases from fuel salt would be necessary to calculate the released dose from a containment rupture or bypass accident, all of the gases/vapors released act collectively to cause pressurization of the containment layer. If the bulk fuel salt temperature remains below its boiling point, then the salt vapors emerging from the fuel salt will result in less than an atmosphere of added pressure. The fuel salt boiling point will be hundreds of degrees above normal operating temperature and will not lower dramatically during use. All proposed MSR designs include a cover gas management system which effectively eliminates the potential for rapid containment pressurization during an accident by removing fission and trapping gases from the fuel salt during normal operation. The removed fission gases are then no longer available for release in an accident involving a breach in the fuel salt or cover gas boundary.

Corrosion and erosion are two mechanisms by which fuel salt can damage its container material. Oxidizing the structural material atoms into a fluoride or chloride salt is a primary corrosion mechanism in halide salts. The salt's propensity to oxidize materials is described by its redox potential. Fluid erosion can be substantially increased by suspended solids within the fluid. Therefore, any particulate content of fuel salt is a property of interest in modeling accident initiation at MSRs. The main cause of particulate loading in MSR fuel salts is the development of a solid phase material that results when fuel salt solubility limits are exceeded.

The thermophysical properties of fuel salt have significant roles in modeling other accidents that could pressurize outer containment. For example, if spilled fuel salt develops a solid crust upon leaking, it would have a much lower rate of chemically or physically interacting with either lubricants or component coolants. If lubricants or coolants that are used for component and/or structural cooling interact with hot fuel salt and experience a phase change, then containment pressure can increase substantially. These types of interactions would occur more slowly with a crusted fuel salt spill. Also, some plant design features (such as non-lubricated seals and bearings) could substantially limit the potential for these accidents by reducing the amount of fuel salt property information required as part of qualification. Contact with hot fuel salt could ignite hydrocarbon lubricants in an oxygen environment. An inert containment environment would minimize the potential for fire. MSRE operated with a 95\% nitrogen environment to avoid the potential for hydrocarbon lubricant fires [13, p. 178]. MSRs can by design limit the amount of water or other coolants with the potential for phase change pressurization in or around containment. Some MSR designs include exterior water cooling of the outer containment layers. An event which causes a rupture of both the containment cooling water system and the fuel salt container could result in significant pressurization. Simultaneous rupture of both the fuel salt container and the structural cooling water system was the maximum hypothetical accident for the MSRE. Although it was not employed at MSRE, the common design practice to limit potential pressurization from this double rupture accident is to segment the cooling water system into multiple independent tubes, several of which would need to rupture to significantly pressurize containment. Reactor designs with limited amounts of cooling water available would need less information about fuel salt properties to enable adequate modeling of accident progression. 
Fuel salt heating of the containment atmosphere following leaking from the salt's normal boundary is also a credible means to increase containment pressure. The degree and mechanisms to which leaking fuel salt intermixes with the atmosphere are determined by its thermophysical properties; that is, a more viscous fuel salt would spray less following the rupture of a pump outlet line. Directly heating the containment atmosphere beyond the structural limits of a steel structure with relatively thin walls (few atmospheres) would require temperatures that could only be achieved with inadequate decay heat removal. Sudden contact with large quantities of hot fuel salt would also provide a thermal shock challenge to outer containment layers. Distance between the hot fuel salt and the outer containment layers would reduce this challenge.

\subsubsection{Inadequate decay heat removal}

Fuel salt remains the primary heat transfer medium in MSRs under accident conditions. All known MSR designs employ some form of natural circulation-based decay heat removal for loss-of-forced-cooling accidents. The requirement to remove decay heat from the salt remains, even if the salt has been removed from the reactor vessel (e.g., sent to a drain tank). Consequently, adequate knowledge of liquid fuel salt heat transfer properties is necessary to ensure that the heat transfer mechanisms can remove the decay heat.

Convection, and to a limited extent, conduction, provide heat transfer from fuel salt. Radiative heat transfer from the hot reactor vessel to the cooling wall is also an important mechanism for designs that employ reactor vessel auxiliary cooling system (RVACS) cooling. Thermal radiation from the surface of a spilled hot fuel salt pool can also provide significant cooling; therefore, knowledge of the fuel salt pool's optical emissivity is required. While clean salt can be nearly transparent, salt containing large quantities of fission products will be effectively opaque when transitioning from volumetric to surface emission.

Insoluble fission product elements will plate out onto the salt-wetted SSCs. If the fuel salt has been drained from the primary loop, then the decay heat produced by the plated out materials may be sufficient to heat the boundary surfaces above their intended service temperatures $[15,16]$. Failure of the normally salt-wetted reactor coolant boundary materials due to heat-up from the intense radioactivity of the plated out materials following salt removal would provide a leakage path into the outer containment for any remaining radioactive vapors or gases in the vessel or piping. Some MSR design variants may require passive decay heat removal from the reactor vessel and piping, even after the fuel salt has been drained.

The specific values of the liquid salt heat transfer parameters required for any particular fuel salt are design dependent. Also, the amount of decay heat produced in the cover gas handling system vs. that remaining in the fuel salt is design dependent. In some designs, the cover gas handling system will require substantial safety-significant heat rejection.

The fuel salt parameters that must be monitored to ensure the continued adequacy of natural circulationbased heat removal are the traditional temperature- and compositional-dependent set for liquid heat transfer characteristics: liquidus temperature, viscosity, density, and heat capacity. Additionally, phase development and separation must be monitored to ensure that the fuel salt remains a single-phase Newtonian fluid. Radiative cooling can be significant for spilled fuel salt pools, so emissivity should also be included in the fuel salt properties. For immobile material (i.e., frozen or plated out materials), thermal conductivity is also an important heat transfer property. Changes in parameter values over time must be monitored to assess whether the changes are in alignment with modeling expectations and whether the values would reasonably be anticipated to go outside of acceptable bounds prior to the next measurement. The rate of change in value also provides guidance on how frequently the parameter should be measured and the required measurement uncertainty band. 


\subsubsection{Unintended criticality}

Thermal spectrum MSRs generally require heterogeneous configurations with adequate moderation to achieve criticality. Consequently, these MSRs are less vulnerable to unintended criticality than fast spectrum MSRs. In MSRs that maximize fissile material loading, under some overcooling accident scenarios, the fuel salt initially becomes cooler, potentially resulting in plate out of fissile materials in the colder parts of the system, which could eventually plug the flow path. Build-up of fission products could also result in exceeding fissile material solubility limits and local fissile material plate out at the coldest part of the loop. The localized concentration of fissile materials could result in criticality occurring outside the core region. The localized heating could then result in failure of the fuel circuit, producing a leak and leading to the consequences described in Section 3.2.1.1. Understanding fuel salt phase and the solubility relationships as a function of temperature, especially for fissile materials, is key to maintaining adequate operating margins to avoid this accident.

\subsubsection{Tritium permeation}

Tritium can diffuse through structural alloy walls when their temperature exceeds $300^{\circ} \mathrm{C}$ [17]. All MSR fuel salts will contain some tritium following initial start-up. Fuel salts that contain lithium or beryllium will produce much more tritium than other salts. The reactor vessel, the first stages of the cover gas handling system, and the primary heat exchanger will all be at temperatures above $300{ }^{\circ} \mathrm{C}$. Outer containment layers temperatures, however, are unlikely to exceed $300{ }^{\circ} \mathrm{C}$ under normal operation temperatures. Hence, the primary vulnerability for tritium release to publicly accessible areas is via diffusion through the thin walls of the primary heat exchanger. Tritium release through intact barriers is primarily an issue for normal operations, and different technology options exist to prevent its uncontrolled release. However, additional tritium may be released under accident conditions due to an increase in the temperature of the graphite moderator (which acts as a temperature-dependent tritium trap), an increase in the temperature of the boundary layer, thus increasing the diffusion rate, or via diffusion through natural circulation decay heat removal heat exchangers that are not normally operating. Tritium release prevention mechanisms are not addressed further in this document.

\subsection{FUEL SALT PROPERTY INFORMATION NECESSARY TO SUPPORT A LICENSING SUBMITTAL}

When obtaining a reactor operating license or design certification, fuel salt thermophysical and thermochemical properties are important for compliance in multiple areas of the Code of Federal Regulations. The information necessary to comply with reactor safety, MC\&A, and radioactive waste form and quantity regulations will all be part of the approval process. Radionuclide release limits are covered under 10 CFR Part 20. Reactor safety during power production is covered under 10 CFR Part 50 (or 52). Requirements for safe handling of nuclear materials outside of the reactor is covered under 10 CFR Part 70 (i.e., before and after usage). 10 CFR Part 72 covers longer term independent storage. 10 CFR Part 74 provides the requirements for nuclear MC\&A, which is relevant for all parts of the fuel cycle. The information needed to support the elements for MSR fuel licensing not directly related to power production is not significantly different from that needed for solid fuel systems, as the fuel salt will be solid prior to its loading into the reactor and after it cools sufficiently following its removal. Nevertheless, most prior solid fuel qualification has been of oxides or metals contained in rods. Therefore, a brief outline of impact of fuel salt properties on the nonoperational elements of MSR fuel salt licensing is provided. 


\subsubsection{Safety during Reactor Operation}

Adequate knowledge of the fuel salt thermophysical and thermochemical properties must be available to ensure that the fuel salt continues to adequately perform its safety functions, as discussed in Section 1.1.

\subsubsection{Retain radionuclides}

When monitoring the location of any released radionuclides, their chemical forms and quantities are key elements for demonstrating adequate safety. The degree to which salt retains radionuclides under normal operating conditions provides input to the performance requirements of the cover gas handling system and to the potential source term for accidental releases. The degree to which radionuclide retention changes under accident conditions (chiefly increasing temperature) is also an important input to accident progression modeling tools, as are the chemical and physical forms of any releases.

Vaporization increases with increasing temperature. Consequently, fuel salts at higher temperatures will release a larger amount of radioactive material into the vapor phase. The thermochemical and thermophysical processes providing increased vapor pressure with increased temperature over a chemical mixture (fuel salt pool) are classical and well understood. The potential safety impact of the fuel salt vaporization depends on the particular MSR design. Some MSR designers have elected to only vent the noble fission gases, which prevents pressurizing the inner containment layer while productively capturing the heat from the other fission products into the power cycle. Other designers have elected to strip volatile vapors and aerosols from the cover gas during normal operations, thereby reducing the amount of radioactive material available to be released during fuel salt loop accidents and also minimizing the compositional changes to the fuel salt due to fission product build up.

In both design variants the reactor cover gas is maintained at low pressure during normal operations, and the designs incorporate pressure venting to a larger containment volume such as a decay tank or a volatile stripping system. The increased volatilization from the fuel salt that occurs as temperature increases during accidents can result in large increases in internal pressures if the bulk boiling temperature of the fuel salt is reached. High temperature and/or high pressure in excess of design limits could structurally damage the reactor coolant boundary. Consequently, the fuel salt properties that must be monitored to model the progress of over-temperature accidents, as well as the radionuclide release impact of such accidents, include the boiling point of the salt, as well as the salt isotopic composition and heat transfer properties.

Measuring the radionuclide retention of the fuel salt at various temperatures is important to establishing the potential source term for accident evaluation, ensuring that the cover gas handling system capacity is appropriate, modeling the changes in the reactor physics resulting from build-up of fission products, and appropriately compensating for changes in the fuel salt chemistry. Most of the needed vapor evolution measurements can be performed with nonradioactive or minimally radioactive isotopes for those elements that do not have nonradioactive isotopes, as volatilization is a thermophysical process and is not significantly impacted by isotopic speciation. Aerosol releases from fuel salts could also become an important concern if they can result in pressurizing the reactor vessel or cover gas head space due to blocking flow passages. Aerosol releases are only of direct safety significance if the products go beyond the containment barriers. Aerosols do not travel long distances unless suspended in a carrier stream, so they would settle or plate out on surfaces locally in MSRs which lack high-velocity gas streams.

A principal function of the fuel salt container is to retain radionuclides. Interaction between the fuel salt and the container is governed by the salt's composition and temperature. Fuel salt container alloy elements are in their most reduced state in the alloy. Non-oxidative dissolution of container alloy elements into halide fuel salts at operating temperatures is small, so the container elements must be 
oxidized for significant corrosion to occur. The capacity for a material to oxidize or to reduce materials is described by its redox potential. The fuel salt's redox potential is thus key to describing its corrosivity. Additionally, some fission products (notably tellurium) have redox-dependent solubility in the fuel salt. Plating out of fission products onto the container surfaces can have beneficial or deleterious effects on the alloy properties. Tellurium plates out under oxidizing conditions and embrittles the surface grain boundaries of nickel-based structural materials [18]. Consequently, maintaining fuel salt in a reducing condition provides a dual benefit of minimizing corrosion and avoiding surface embrittlement. The fission process is oxidative (meaning that the fission products require fewer halide ions to create neutral molecules than the $\mathrm{U}^{4+}$ salt, resulting in an excess of halide ions). Consequently, fuel salt redox will require periodic adjustment to avoid becoming excessively corrosive.

\subsubsection{Reject decay heat}

Providing reasonable assurance of the continued capability to reject decay heat requires monitoring changes in the natural convection heat transfer properties of the fuel salt. The capability of a particular reactor design to adequately reject decay heat with fresh fuel salt will initially be established through thermal and hydraulic modeling and experimentation. Fuel salt decay heat rejection via natural circulation cooling will take place by Laminar flow of the fuel salt across a heat exchange surface. Bonilla [19] developed a parameter group that describes the effectiveness of a coolant to dissipate heat via natural convection in the Laminar flow regime:

$$
\underset{\text { Transfer Effectiveness }}{\text { Laminar Heat }} \propto\left(\frac{\beta \rho^{2} c_{p}}{\mu}\right)^{\frac{1}{2}},
$$

where $\beta$ is the volumetric expansion coefficient $\left(\frac{1}{\rho} \frac{d \rho}{d T}\right), \rho$ is the density, $\mathrm{c}_{\mathrm{p}}$ is the heat capacity, and $\mu$ is the viscosity.

Natural circulation heat transfer from fuel salt increases with increasing temperature. This is because the heat transfer improvement that occurs due to the decrease in viscosity is larger than the heat transfer reduction that occurs due to the decrease in density. Salt heat capacity does not vary strongly with temperature. Viscosity decreases exponentially with reciprocal temperature, whereas density decreases linearly with temperature [20]. The heat transfer also increases due to the higher driving temperature difference between the fuel salt and the external environment.

Radiative emission from any material increases with the absolute temperature to the fourth power and is linearly proportional to the surface emissivity. For accident situations involving radiative heat transfer from a spilled fuel salt pool to outer containment walls, the radiative heat flux is such a strong function of temperature that changes to fuel salt emissivity would be overcome by only a few degrees of increased temperature. In other words, changes to fuel salt properties with use will not significantly impact its ability to reject heat through radiative cooling. Intervening smoke, mists, and/or aerosols can significantly reduce the effectiveness of radiative heat transfer between a spilled salt pool and cooling walls. The optical density of fuel salt vapors at accident temperatures needs to be assessed to enable modeling of radiative heat transfer from spilled fuel salt. Note, however, that hot fuel salt interaction with materials outside of the primary loop (insulation, concrete, organic structural coolants or lubricants) may generate airborne foulants, which could significantly impede radiative heat transfer from spilled fuel salt.

The consequences of fuel salt temperature increase under accident conditions determines the required decay heat rejection properties. Fuel salt is a Newtonian fluid that is well away from its freezing and boiling temperatures during normal operation. Consequently, fuel salt does not exhibit any cliff edge changes in its heat transfer properties at or near operating conditions. Fuel salt will boil hundreds of 
degrees above operating temperatures, progressively larger amounts of radionuclides will evaporate from the fuel salt free surface at increasing temperatures, and the fuel salt container alloy will progressively weaken as the temperature increases. For all known nickel-based alloys and reasonably anticipated fuel salt compositions, structural material weakening will be the parameter that limits the allowable fuel salt temperature rise without increasing accident severity (barrier failure). Fuel salts have hundreds of degrees of margin above operating temperatures to bulk boiling, and enhanced evaporation of radionuclides is only important in terms of increasing potential accident severity to the degree that it increases the internal pressure on the container alloy.

The salt container must maintain its geometry for the fuel salt flow to result in the design heat transfer. Known and reasonably anticipated structural alloys do not have a relevant absolute temperature limit; instead, they have an integrated time, temperature, and stress limit. The fuel salt container alloy's structural strength will decrease at increasing temperature. The forces on the alloy will cause it to deform (creep) as it operates under mechanical stress for an extended period at elevated temperature. Even under normal operating conditions, the salt-wetted container material will slowly creep. All high-temperature service metallic components are designed with some creep margin. The high-temperature portion of the American Society of Mechanical Engineers (ASME) Boiler and Pressure Vessel Code recognizes that over a component's operating life, some creep deformation is likely. A typical service criterion for determining allowable stress and temperature combinations is $1 \%$ deformation in 100,000 hours of service life. A limited duration temperature excursion at constant stress will accelerate the material creep, which would only become unacceptable for continuing service if the total creep exceeds the design allowance. Unacceptable container deformation due to creep or stress-rupture would not be anticipated if the component creep deformation remains within the design allowance.

Fuel salt with a build-up of materials resulting in a higher viscosity at operating temperature would provide equivalent natural circulation decay heat rejection at a higher temperature than fresh fuel salt. The higher temperature would increase the natural circulation heat transfer by decreasing the salt viscosity and providing a higher temperature difference to the heat sink. The reactor would need to be designed to safely accommodate the loss of forced flow accident with minimal creep in the thin-walled heat exchanger tubing for any reasonably anticipated salt viscosity. An increase in the fuel salt viscosity at operating temperature will increase the amount of pumping power required to provide an equivalent mass flow rate. Online salt property measurements (such as those obtained by applying ANSI/HI 9.6.7, Effects of Liquid Viscosity on Rotodynamic Pump Performance) could alternatively be used to provide a continuous estimate of the fuel salt viscosity change based upon the change in the required pumping power to maintain a constant flow rate.

Fuel salt viscosity, density, and heat capacity as a function of temperature are thus key measurements and elements of a fuel salt property database to ensure the continued ability to passively reject decay heat. Bonilla's natural circulation heat transfer effectiveness parameter group and the pumping power viscosity correlation method only remain effective if the fuel salt remains a single-phase Newtonian fluid. Upon exceeding solubility limits of either actinides or fission products, the fuel salt may separate into immiscible liquid phases, or more likely, a component will solidify out of the melt. Multiple components of the fuel salt mixture compete for solubility. Increasing the amount of some lanthanide fission products decreases the solubility of actinides in the melt [21]. Fast-spectrum reactors require higher concentrations of fissile materials and are thus more likely to operate near the solubility limits of the fissile materials, although thermal spectrum reactors may operate with a smaller amount of higher fissile content salt. Solubility of some elements is a function of the salt redox condition. In MSRE-type fuel salt, tellurium remains dissolved in the fuel salt under reducing conditions, but it plates out onto surfaces under more oxidizing conditions [22]. A database of fuel salt thermochemical properties will be key factor to assess how close a fuel salt mixture is to having components plate out or separate into multiple liquid phases. 


\subsubsection{Provide net negative reactivity feedback}

The fuel salt is required to provide net negative reactivity feedback with increasing temperature in power range of operation (10 CFR Part 50, Appendix A - GDC 11). Reactor physics for any reactor is both computationally predicted and experimentally validated during the design process. The predictions are confirmed during start-up testing by performing reactor physics confirmatory experiments. MSRs will follow a conventional reactor physics development and design route to ensure that the initially loaded fuel system provides a net negative reactivity feedback. The safety requirement for continued operation is to provide assurance that the change in the fuel salt composition over time has not changed the net negative reactivity feedback. Thermal spectrum MSRs will increase their fissile material loading over time to compensate for the build-in of neutron absorbing fission products, and all MSRs will change their fuel salt fissile isotopic composition as materials are bred in (or added) and burned out (or removed).

Experimental validation of reactor physics simulations performed with used fuel salt provides assurance that the reactor system will continue to have net negative reactivity feedback with the increased fissile loading and change in fissile isotopic composition. Reactor feedback properties can be obtained by monitoring the change in the neutron flux due to a small, rapid reactivity stimulus. Controlled reactivity stimulus can be provided through various means without expensive design or operational changes. For example, control rod jogging or oscillating reflectors have typically been used to provide the reactivity stimulus needed to evaluate reactor dynamics. MSRs afford additional options to provide the reactivity stimulus. Some designs incorporate bubble flow through the core to strip gaseous fission products from the fuel salt and to serve as a rapid-acting reactivity control. Variable speed primary pumping may also allow for impressing a small oscillation onto the salt flow velocity, which would provide a small reactivity oscillation due to the resultant input temperature variance. The reactivity impact of a controlled fuel salt addition (and removal) also provides information on reactor feedback properties.

\subsubsection{Safe Handling and Storage of MSR Fuel Salt Nuclear Materials - 10 CFR Parts 70 and 72}

Fuel qualification encompasses the role of the fuel in nonoperational aspects of nuclear plant safety. More specifically, the fuel salt properties are part of the integrated safety analysis required under 10 CFR 70.62. Fuel salt nuclear material handling safety is within the scope of fuel salt qualification to the extent that it contributes to any event sequence that could result in dose to a member of the public beyond that specified in 10 CFR 20.1301. The fuel salt cover gas radionuclide content and mobility are relevant to fuel salt qualification until the radionuclides have been trapped in a stable waste form. Similarly, the properties of plated out fission products remain relevant to fuel salt qualification until they have been removed from the fuel salt loop. Residual fuel salt droplets on used components and/or small fuel salt samples extracted for analysis do not impact the overall safety of the facility, as small quantities of solid salts lack adequate radionuclide mobility driving force to result in off-site release, so consequently, they fall outside the definition of fuel qualification. The properties of more substantial amounts of used fuel salt (analogously to an LWR used fuel pool), while still liquid, would be within the scope of fuel salt qualification and must be addressed as part of compliance with 10 CFR Part 50 (or 52) to the extent that the fuel salt could participate in an event sequence resulting in offsite release. However, the requirements for fuel salt performance, once solidified in independent long-term storage, would be equivalent to those for other solid used fuel forms as governed by 10 CFR Part 72. Larger quantities of used flush salt would also be anticipated to be capable of being part of an event sequence with offsite dose consequences.

The overall hazards of MSR fuel processing operations were recently reviewed [23]. The at-plant portion of the fuel handling hazards are relevant to fuel salt qualification. Fresh MSR fuel will be a solid fissile or fertile bearing salt. As with other fresh fuel forms, fresh MSR fuel salt will present minimal radioactivity hazard unless the salt is derived from previously used fuel. 
Used MSR fuel will contain substantial amounts of fission product and actinide salts. The fuel salts will not be chemically stable under the intense residual radiation field once the salt has cooled down sufficiently so that chemical recombination no longer dominates radiolysis. For fluoride salts, this occurs at about $150{ }^{\circ} \mathrm{C}[24,25]$. Chemical recombination into other solid forms does not significantly impact the potential for offsite dose. Also, $\mathrm{UF}_{6}$ would be created by fluorination of $\mathrm{UF}_{4}$ if the fuel salt is reheated to $200{ }^{\circ} \mathrm{C}$ [26]. Thus, it is important not to reheat the salt in an attempt to recombine radiolytically generated fluorine gas, as was periodically done for the stored MSRE fuel. Most isotopes of uranium have low radiotoxicity, so they only provide limited direct radiation dose hazard, but redistributing fissile materials can result in inadvertent criticality and/or increased availability of separated fissile materials. Uranium chloride does not have a low temperature gaseous phase, so it does not exhibit equivalent behavior. Both salt systems, however, can generate radiolytic halide gas $\left(\mathrm{F}_{2}\right.$ or $\left.\mathrm{Cl}_{2}\right)$, potentially pressurizing their containers. Therefore, the safety analysis for long-term used fuel storage casks will need to address radiolytic generation of fluorine gas or chlorine gas. Both chloride and fluoride salts have appreciable water solubility. Used fuel salt will have cooling, shielding, and chemical isolation requirements. Water solubility of the used fuel must be included in the fuel salt property information if used fuel salt being exposed to water would be a credible accident. Heat transfer from solidified used fuel will primarily be through conduction to a cooling surface, so thermal conductivity and decay heat generation rate will be the principal heat transfer properties of interest.

Used fluoride salts will also require cover gas management to prevent pressurization and to appropriately manage any released gases. No used chloride fuel salt has ever been stored for long durations, and only one type of used fluoride salt fuel has been stored for decades, so additional testing will be required to develop high confidence that their physical and chemical behaviors are sufficiently understood so that they can be adequately modeled under accident conditions.

Improperly performed fuel processing can also result in accidents with the potential for offsite doses. An example of processing failure with the potential to escalate into a more serious operational accident would be carrying over bismuth from reductive extraction fuel processing back into the fuel circuit. Bismuthbased reductive extraction remains a key technology for in enabling breeding gain in the $\mathrm{Th} / \mathrm{U}$ fuel cycle in fluoride salt MSRs. Bismuth within the fuel salt would dissolve any nickel-based container alloy, resulting in a first containment layer failure LOCA. The nature and amount of fuel processing is design dependent, so generalized safety requirements can only be developed at the reactor subclass level (e.g., for fluoride salt reactors employing the $\mathrm{Th} / \mathrm{U}$ fuel cycle). Carry over of fluorinating or chlorinating agents into the reactor could also significantly oxidatively corrode the container alloy, eventually resulting in a rupture of the container. Any fuel salt will be required to meet a chemical compatibility specification to be able to be introduced into the fuel salt circuit.

Used fast-spectrum MSR salt can contain sufficient amounts of fissile material to result in criticality if moderation and or favorable geometry is created. The composition of used fast spectrum MSR salt, including both fissile materials and neutron absorbers, will also be part of the fuel salt specification.

\subsubsection{Material Control and Accountability - 10 CFR Part 74}

Material control and accountability (MC\&A) is a broad topic, with only a limited portion of its information being relevant to fuel qualification. Fuel qualification is limited to the impact of the fuel salt on the overall safety of the facility. Fissile material accountancy is related to facility safety in both the means to perform accountancy and in the safety impact of changes to the facility design to accommodate MC\&A. MSRs will require substantial shielding between the fuel salt and the environment. The environment within containment will be too intensely radioactive for human entry following initial reactor operation. Much of the material accountancy will consequently take place as fissile and/or fertile materials enter or leave containment. The handling and positioning of used fuel salt for performing fissile 
material accountancy has the potential to result in inadvertent criticality at these entry points due to the creation of a favorable geometry or enhanced moderation. The accident would be more likely if the fissile material distribution in used fuel salt changes following extraction from the active fuel salt loop (i.e., if fuel salt fissile material segregates during freezing). Consequently, the fuel salt solubility and phase transformation properties will be part of the fuel salt properties database required for qualification.

\subsubsection{Waste Forms and Quantities - 10 CFR Part 60}

In undamaged LWR used fuel, the fission products are retained with the fuel, so the safety impact of the used fuel assemblies accounts for the fission product radionuclides, as well as the fissile materials. Including LWR fission products within used fuel in the elements of LWR fuel qualification, along with the NRC definition of high-level waste as including "waste materials remaining after spent fuel is reprocessed" [27], implies that MSR fuel salt qualification must encompass the facility safety impacts of all fission products following their removal from the primary loop. However, LWR fuel qualification does not encompass the potential safety impact of the resin bed fission product radioactive waste produced by leaking fuel elements. Consequently, a key decision required in order to bound MSR fuel qualification requirements is to determine when the potential safety impacts of fission products that leave the main fuel salt body cease to be considered relevant to fuel salt qualification.

This report relies upon the analogy with the LWR resin beds and cladding, and it assumes that fuel salt qualification encompasses the potential impact of those fission products that remain within the first containment layer during normal operations. Thus, the potential for the cover gas system to result in offsite doses remains relevant to fuel qualification until its radionuclides are trapped in a stable waste

form or bottled for decay storage, as in the case of ${ }^{85} \mathrm{Kr}$. Similarly, the plated out fission products on the interior surfaces of the container alloy are relevant to fuel salt qualification. However, once the components have been removed from service, the radionuclide properties are no longer considered relevant for fuel qualification. The consequences of flaking off of plated out radionuclides from component surfaces during local storage for decay is not considered relevant to fuel qualification. With the suggested limitation to the scope of fuel salt qualification, only the properties of the main body of used fuel salt would be relevant to fuel qualification.

Used fuel salt will require adequate shielding, decay heat removal, criticality control, and potentially $\mathrm{F}_{2}$ or $\mathrm{Cl}_{2}$ and $\mathrm{UF}_{6}$ pressure venting as described earlier in Section 3.3.2 of this report.

\subsection{FUEL PROPERTIES DATABASE}

The fuel properties database contains the fuel salt thermochemical and thermophysical property information needed to model the safety aspects of fuel performance under both normal and accident conditions. While accident evaluation adds fields to the database, heat transfer and criticality are key issues during both normal operations and accident conditions. Consequently, the same fuel salt property information is required to model both normal and accident condition performance, albeit over different temperature ranges. The rationale underlying inclusion of each field in the database is addressed in Sections 3.1 and 3.2 of this report. A particular reactor design's fuel salt system may have additional technical specifications not covered in the fuel salt property database, such as the acceptable contaminant (e.g., bismuth) concentration, that are only relevant to specific accident sequences.

The fuel salt property data fields for each salt are as follows:

1. Elemental and isotopic composition

2. Liquidus temperature (temperature above which the material is completely liquid) 


\section{Boiling temperature}

4. Viscosity as a function of temperature

5. Density as a function of temperature

6. Heat capacity as a function of temperature

7. Thermal conductivity below the liquidus temperature as a function of temperature

8. Phase stability composition ranges (how much variance in composition would be required to result in development of a separated phase)

9. Suspended particulate content

10. Total vapor pressure, component vapor pressures, and optical density of vapor as a function of temperature

11. Elemental speciation / redox potential

\section{Emissivity}

The effective redox potential will be represented in the database through thermodynamic equilibrium calculations. For most fuel salts, the concentration ratio of the $\mathrm{U}^{4+}$ to $\mathrm{U}^{3+}$ ions will be a convenient representation of the redox state.

The MSR operational safety characteristics presented in Figure 1 do not map precisely to the fuel salt database fields, as some fuel salt characteristics are important to longer term safety characteristics such as redox and corrosion or suspended particulates and erosion, and others only become important during accident conditions for particular plant designs such as in optical density of fuel salt vapors.

10 CFR Part 50, Appendix A, GDC 1 dictates that the maximum allowable uncertainty of the property data will be determined by the safety implication of the data's imprecision or inaccuracy. 10 CFR Part 50, Appendix B provides the QA requirements for obtaining fuel salt property information.

The thermochemical and thermophysical properties of halide salts have been investigated for decades. Consequently, a substantial amount of salt property information already exists, as well as methods for estimating currently unavailable information. However, little of this information was developed under an Appendix B or equivalent QA program. Therefore, a substantial data and methods validation effort is needed before the existing information can be appropriately used to support a nuclear reactor safety case. The US Department of Energy (DOE) Office of Nuclear Energy (NE) is sponsoring the development of a broad molten salt thermodynamic database which is intended to eventually span the potential composition ranges of all likely fuel salt compositions [28].

Fuel salt property measurement procedure standards have generally not been endorsed or used previously to generate nuclear safety-related data. Hence, measured data will require additional validation beyond assuring that the acquisition followed an endorsed standard.

\subsubsection{Simulation of Fuel Salt Properties Between Measurement Points}

Fuel salt property measurements are made for discrete compositions and temperatures. The composition of fuel salt in an MSR will continuously be changed during operation deliberately and as a consequence 
of operation. The fuel salt thermophysical and thermochemical properties are determined by the composition. The set of measurements for multiple compositions and temperatures are used to construct a model for the property variance with composition and temperature. Properties can be interpolated between measured data points using the developed model. Since none of the properties exhibits cliff edge effects under operating conditions, bounding measurements can be used to provide reasonable assurance that relevant properties remain within an acceptable range. Outside of operating conditions, fuel salt properties can exhibit threshold responses like boiling or freezing. Consequently, extrapolations beyond bounding property measurements cannot be used to provide reasonable assurance of adequate safety.

\subsubsection{Evaluation of Safety Significance in Gaps in Fuel Property Data in Terms of Accident Analysis}

The required precision for any individual salt characteristic will largely depend on the design characteristics. Both accident sequences and accident progression modeling tools would be necessary to appropriately assess the required fuel salt parameter data precision.

The large safety margins characteristic of MSRs, however, provide some insight into the precision of the required characteristics. For example, MSRs typically operate hundreds of degrees away from the fuel salt boiling point, and the container material's softening temperature would also be substantially below the fuel salt boiling point. Consequently, exactness in the fuel salt boiling point would have minimal impact on the overall plant safety. Similar arguments can be made for other fuel salt parameters. An incorrect fissile material isotopic fraction becomes important as it impacts the net reactivity feedback. For designs with a substantial net negative reactivity feedback margin, fissile isotopic distribution will have substantial allowable uncertainty.

\section{FUEL SALT SYSTEM GLOSSARY}

This glossary is limited to specialized terms involved with MSR fuel salt system qualification for cases in which using solid fuel terminology results in ambiguity. For example, reactor coolant could be interpreted as the material used to remove heat from the reactor core or the material used to remove heat from the fuel. This glossary preserves the safety intent of pre-existing definitions to the extent possible, only providing clarification where the structures of an MSR are sufficiently different from those of LWRs so as to represent a potential source of confusion. For example, containment structure is defined in the $\mathrm{NRC}$ full text glossary [4] as follows:

A gas-tight shell or other enclosure around a nuclear reactor to confine fission products that otherwise might be released to the atmosphere in the event of an accident. Such enclosures are usually dome-shaped and made of steel-reinforced concrete.

Also, 10 CFR Part 50, Appendix J, defines primary reactor containment as the structure or vessel that encloses the components of the reactor coolant pressure boundary, as defined in $\S 50.2$, and serves as an essentially leak-tight barrier against the uncontrolled release of radioactivity to the environment. MSRs are low-pressure systems, so they may not employ a physically similar structure, but they must perform the same safety function.

A similar glossary providing a set of terms related to liquid fueled reactors was developed for the final interim staff guidance on aqueous homogeneous reactors [29]. Also, a recommendation for which portions of an MSR constitute its fuel salt system is provided in the introduction to this report. Non-MSR specific technical terms have their customary meanings from the scientific literature (e.g., Newtonian fluid). Reactor developers may choose to develop design-specific definitions when they develop their design-specific principal design criteria. 
MSRs have a wide variety of potential configurations. The same safety function may be performed by different structures in different design variants, and the same material may perform multiple safety functions. Consequently, this report describes reactor SSCs in terms of the relevant safety function being considered, recognizing that in some designs, the same component will consequently be described using multiple terms. For example, the reactor vessel also forms part of the reactor coolant boundary and the innermost containment layer.

Cover gas system boundary means the portion of an MSR's innermost radionuclide containment layer that is not wetted by the fuel salt.

Fuel salt means the material containing fissionable isotopes that sustains reactor criticality, including materials that have left the salt but could reasonably be anticipated to be reincorporated into it.

Primary reactor containment means the outermost low-leakage pressure retaining structure credited to retain radionuclides in the event of an accident.

Reactor coolant (ARDC 33) means the material used to transfer energy away from the reactor core (aka fuel salt).

Reactor coolant boundary (ARDC 32) or reactor coolant pressure boundary (GDC 32) means the innermost physical barrier surrounding the reactor coolant (aka fuel salt).

Reactor core means the region where nuclear criticality occurs during normal operation.

Reactor vessel means the structure that contains the core during normal operation.

\section{GUIDANCE NEEDED TO ADOPT AND IMPLEMENT NEW APPROACH}

Multiple potential MSR vendors are entering into a detailed design phase. These stakeholders have indicated that near-term guidance for a fuel salt qualification approach based on property measurements such as described in this report would be useful. Establishment of a uniform set of fuel salt qualification expectations would improve regulatory efficiency by making similar safety judgements once for multiple applicants. Providing guidance on MSR fuel qualification requirements would also help to inform and structure DOE-NE research and development efforts, providing the supporting technical information necessary to develop an adequate fuel salt properties database.

Key elements of fuel salt system qualification guidance could include the following:

1. Use bounding condition performance and accident models to establish acceptable fuel specifications.

2. Obtain an adequate understanding of the safety-significant liquid salt fuel system properties by

a. creating a fuel salt fuel salt thermophysical and thermochemical properties database spanning the acceptable range of fuel salt composition, thermochemical, and thermophysical properties suitable for design purposes and safety performance assessment; and

b. periodically measuring fuel salt composition (and initially measuring thermochemical and thermophysical properties) during reactor operation to demonstrate that the key properties remain within an acceptable envelope. 
3. Establish liquid fuel properties and performance requirements independently of scale as compared to a discrete fuel element basis for solid fuels.

4. Establish that potential safety issues of radionuclides that are no longer part of the fuel salt system (e.g., those trapped in waste forms) are not relevant to fuel salt system qualification.

MSR fuel systems have substantially different safety function allocation and accident progression sequences compared to those of LWRs. Consequently, attempting to apply existing LWR fuel system qualification guidance to MSRs can result in significant confusion for prospective applicants and NRC staff. Regulatory clarity and efficiency would be increased by describing acceptable methods for liquid salt fuel qualification and defining the data that the staff would need to receive to enable review of license applications. This would also inform DOE-NE MSR technical support activities that seek to produce generic molten fuel salt property information that is useful to any reactor developer.

MSRs are currently under development by several US companies, with reasonable projections of licensing submittals within the next decade. LWR license applicants can rely upon an extensive body of regulatory guidance. Both accident-tolerant LWR fuel systems [30] and other advanced solid fuel reactors [31] [32] have sufficient guidance available to be able to develop fuel qualification reports. Providing appropriate guidance on liquid fuel salt system qualification would minimize the regulatory uncertainty for future MSR license applicants.

The proposed fuel salt system qualification guidance would describe acceptable methods for acquiring the information needed for fuel salt system qualification. The guidance would include acceptable methods to (1) acquire the information needed for initial plant licensing and (2) to confirm that the fuel salt parameters remain within acceptable boundaries during operation. The proposed fuel system qualification guidance report would include the technical basis of acceptable measurement methods and their capability to provide data to assess achievement of safety functions.

Fuel salt property measurement methods and associated measurement uncertainties will be based upon standard practices and methods to the extent possible. For several parameters, multiple methods can provide similar results. The proposed report will include the technical basis for measurement equivalence. For example, salt redox can be measured electrically or by the concentration ratio of redox-dependent different chemical species. The property measurements can be employed during operation to assess changes and trends in fuel salt properties. For example, changes in pump power and mass flow rate can be correlated to assess reactor coolant viscosity change, or continued net negative reactivity feedback can be demonstrated through frequency response testing.

The DOE-NE MSR national campaign is currently making molten salt property measurements. NRC guidance on liquid fuel salt qualification would focus DOE-NE efforts on generating the safety-related information necessary for the NRC to evaluate reactor safety and would minimize the potential for duplicative or wasted effort.

\section{SUMMARY AND RECOMMENDATIONS}

This report describes a proposed measurements-based, performance-based, technology-neutral MSR fuel salt qualification approach. The report discusses the current approach to fuel qualification that is used for solid fuel reactors and describes how the distinctive aspects of liquid fueled MSRs necessitate a different approach for evaluating the fuel's role in reactor safety. The approach is based on the measurement of fuel salt properties to assure that safety functions depending on these properties are fulfilled. The thermochemical and thermophysical properties of fuel salts depend only on their elemental composition and not on sample size or isotopic composition. Hence, fuel salt property measurements can be made on 
small samples containing the same elemental composition without requiring large quantities of highly radioactive used fuel salt. A key element of the proposed approach is the development of a fuel salt properties database that relates fuel salt composition and temperature to thermophysical and thermochemical properties. Periodically measuring fuel salt composition (and initially measuring thermochemical and thermophysical properties) during operation demonstrates that fuel salt properties remain within acceptable boundaries for the fuel salt to perform its safety functions.

It is recommended that additional guidance on potential acceptable methods be developed to acquire the necessary thermochemical and thermophysical property information, as consensus standards on this subject have not yet been considered for endorsement and may not be fully appropriate for the intended use. It is also recommended that methods be evaluated to assess the quality of existing fuel salt thermophysical and thermochemical data since substantial amounts of halide salt property information is available in the scientific literature but was not developed under a nuclear grade QA program. 


\section{REFERENCES}

1 Paul A. Demkowicz, Bing Liu, and John D. Hunn. 2019. "Coated Particle Fuel: Historical Perspectives and Current Progress, Journal of Nuclear Materials 515: 434-450.

2 US Nuclear Regulatory Commission. 2017. Public Meeting on Improvements for Advanced Reactors, August 3, 2017. Washington, DC, https:/www.nrc.gov/docs/ML1722/ML17220A315.pdf (accessed November 2018).

3 G. F. Flanagan, D. E. Holcomb, and W. P. Poore, III. 2018. Molten Salt Reactor Fuel Qualification Considerations and Challenges, ORNL/LTR-2018/1045, Oak Ridge, Tennessee, https://www.nrc.gov/docs/ML1834/ML18347A303.pdf (accessed September 2019).

4 US Nuclear Regulatory Commission. 2020. "Full Text Glossary." https://www.nrc.gov/readingrm/basic-ref/glossary/full-text.html (accessed June 2020).

$5 \quad 10$ CFR 50.46. "Acceptance Criterion for Emergency Core Cooling Systems for Light-Water Nuclear Power Reactors." Code of Federal Regulations, Title 10, Energy, Part 50.46. Washington, DC.

6 US Nuclear Regulatory Commission. 2007. Standard Review Plan for the Review of Safety Analysis Reports for Nuclear Power Plants: LWR Edition. NUREG-0800. NRC Accession Number ML092330826. Washington, DC.

7 US Nuclear Regulatory Commission. 2007. Combined License Applications for Nuclear Power Plants. Regulatory Guide 1.206. Washington, DC.

8 James A. Lane, H. G. MacPherson, and Frank Maslan. 1958. Fluid Fuel Reactors, Addison-Wesley Publishing Company, Inc., p. 586

9 Blaise P. Collin. 2016. Diffusivities of Ag, Cs, Sr, and Kr, in TRISO Fuel Particles and Graphite, INL/EXT-16-39548.

10 Roy E. Thoma. 1971. Chemical Aspects of MSRE Operations, ORNL-4658, DOI: $10.2172 / 4675946$.

11 J. R. Engel and B. E. Prince. 1967. The Reactivity Balance in the MSRE, ORNL-TM-1796.

12 T. W. Kerlin, 1974. Frequency Response Testing in Nuclear Reactors, Academic Press Inc., New York and London.

13 S. E. Beall, P. N. Haubenreich, R. B. Lindauer, and J. R. Tallackson. 1964. MSRE Design and Operations Report Part V Reactor Safety Analysis Report, ORNL-TM-732.

14 J. H. Buck and W. B. Cottrell. 1952. Aircraft Reactor Experiment Hazards Summary Report, ORNL1407.

15 J. R. Tallackson. 1971. Thermal Radiation Transfer of Afterheat in MSBR Heat Exchangers, ORNLTM-3145.

16 S. Reid. 2017. Tanaka Quantifying the Adhesion of Noble Metal Foulants on Structural Materials in a Molten Salt Reactor, Master's Thesis, Massachusetts Institute of Technology.

17 Piyush Sabharwall, Hans Schmutz, Carl Stoots, and George Griffith. 2013. Tritium Production and Permeation in High-Temperature Reactor Systems, INL/CON-13-28329.

18 J. R. Keiser. 1977. Status of Tellurium-Hastelloy N Studies in Molten Fluoride Salts, ORNL/TM6002, DOI: $10.2172 / 7295251$. 
19 C. F. Bonilla. 1958. "Comparison of Coolants," in Nuclear Engineering Handbook, H. Etherington, Ed., Sect. 9-3, Chap. 6.5, p. 9-93.

20 D. F. Williams, L. M. Toth, and K. T. Clarno. 2006. Assessment of Candidate Molten Salt Coolants for the Advanced High-Temperature Reactor (AHTR), ORNL/TM-2006/12.

21 Victor V. Ignatiev, Mikhail V. Kormilitsyn, Andrey A. Lizin, Alexander V. Zagnitko, Sergey A. Konakov, Alexander V. Merzlyakov, Sergey V. Tomilin, Alexander A. Khokhryakov, and Alexander G. Osipenko. 2016. "Key Experimental Results of the PYROSMANI Project," Procedia Chem. 21 417-424, https://doi.org/10.1016/j.proche.2016.10.058, accessed October 2019.

22 E. L. Compere, S. S. Kirslis, E. G. Bohlmann, F. F. Blankenship, and W. R. Grimes. 1975. Fission Product Behaviour in the Molten Salt Reactor Experiment, ORNL-4865.

23 Joanna McFarlane, Paul Taylor, David Holcomb, and W. P. Poore. 2019. Review of Hazards Associated with Molten Salt Reactor Fuel Processing Operations, ORNL/TM-2019/1195.

24 P. N. Haubenreich. 1970. Fluorine Production and Recombination in Frozen MSR Salts after Recombination, ORNL-TM-3144.

25 L. M. Toth and L. K. Felker. 1990. "Fluorine Generation by Gamma Radiolysis of a Fluoride Salt Mixture," Radiation Effects and Defects in Solids, 112, pp. 201-210.

26 A. S. Icenhour, D. F. Williams, L. D. Trowbridge, L. M. Toth, and G. D. Del Cul. 2001. "An Overview of Radiolysis Studies for the Molten Salt Reactor Remediation Project," Proceedings of Global 2001, Paris, France.

27 US Nuclear Regulatory Commission. 2017. "High-Level Waste," https://www.nrc.gov/waste/highlevel-waste.html, accessed June 2020.

28 J. McMurray, T. Besmann, J. Ard, S. Utlak, and R. Lefebvre. 2019. Status of the Molten Salt Thermodynamic Database, MSTDB, ORNL/SPR-2019/1208.

29 US Nuclear Regulatory Commission. 2012. Final Interim Staff Guidance Augmenting NUREG1537, Part 1, Guidelines for Preparind and Reviewing Applications for the Licensing of Non-Power Reactors: Format and Content," for Licensing Radioisotope Production Facilities and Aqueous Homogeneous Reactors, ML12156A069.

30 US Nuclear Regulatory Commission. 2017. Draft Project Plan to Prepare the US Nuclear Regulatory Commission to License and Regulate Accident Tolerant Fuel. NRC Accession Number ML17325B772, December 14. Washington, DC.

31 C. Marciulescu and A. Sowder. 2019. Uranium Oxycarbide (UCO) Tristructural Isotropic (TRISO) Coated Particle Fuel Performance Topical Report, EPRI-AR-1 (NP) 3002015750, ML19155A173, May 2019.

32 W. R. Reckley. 2016. Draft Report Assessment of the Adequacy of Metallic Fuel Qualification to Support the Licensing of Small Modular Sodium-Cooled Fast Spectrum Reactors (4-S, ARC-100, PRISM), ML16248A002. 


\section{APPENDIX A. IDENTIFICATION OF REGULATORY GUIDANCE IMPACTING MSR FUEL QUALIFICATION}

Many existing nuclear power plants' regulations and regulatory guidance documents are specified in their text as only being applicable to LWRs. However, analogous to the guidance provided in the introduction of 10 CFR Part 50, Appendix A- “"The General Design Criteria are also considered to be generally applicable to other types of nuclear power units and are intended to provide guidance in establishing the principal design criteria for such other units." - the safety-performance objectives for much of the existing body of regulations remain relevant to MSRs. In general, MSRs will require regulations and guidance equivalent to that for LWRs to enable efficient preparation and review of licensing applications.

Some existing regulatory language is performance-based (e.g., 10 CFR Part 50, Appendix S) and would be directly applicable to MSRs, but technology-specific, prescriptive guidance such as the post Three Mile Island section of 10 CFR 50.34 would be confusing to apply when attempting to translate safetyperformance objectives from LWRs to MSRs. Other existing regulatory language would be confusing to attempt to apply to MSRs because of the differences in the physical processes inherent to the reactor classes. For example, 10 CFR 50.2 references "the integrity of the reactor coolant pressure boundary." MSRs lack a pressure boundary, and the fuel salt also serves as a coolant. The existing language does not make it clear whether this would refer to the fuel salt circuit or the unfueled coolant salt loop employed to transfer heat from the fuel salt circuit to the power generating system.

Only a limited set of regulatory requirements is directly pertinent to fuel salt performing its own safety functions. However, fuel qualification includes understanding fuel properties adequately to enable modeling overall plant safety performance under both normal and accident conditions. Consequently, a larger number of regulations have tangential bearing in that they provide requirements for the plant's coolant boundary or other accident scenarios impacted by fuel salt properties.

This document is limited to listing and describing existing regulatory language related to MSR fuel qualification for which the underlying physics of MSRs provides an alternative means to achieve the safety objectives. For example, paragraph (b) of 10 CFR 50.55a requires that "systems and components of boiling and pressurized water-cooled nuclear power reactors must meet the requirements of the ASME BPV Code and the ASME OM Code." While the text of the requirement indicates that it is not intended to be applicable to MSRs, the radionuclide retention issue underlying ASME BPV Code and ASME OM Code compliance is captured for MSRs in SRM-SECY-18-0096 "Functional Containment Performance Criteria for Non-Light-Water-Reactors." However, the ASME BPV Code does not address key fuel salt related stressors for MSRs, namely corrosion and radiation embrittlement. Additional examples where specific regulatory wording requires updating or exceptions to reflect the safety characteristics of MSRs follow.

10 CFR 50.33 and 10 CFR 50.47

The size of the [emergency planning zones] EPZs also may be determined on a case-bycase basis for gas-cooled reactors and for reactors with an authorized power level less than $250 \mathrm{MW}$ thermal.

MSR fuel performance relies upon specified acceptable radionuclide release design limits (SARRDLs) like high-temperature gas-cooled reactors (HTGRs), so an MSR's EPZ may more appropriately also be determined on a case-by-case basis.

10 CFR 50.34 (D) and 10 CFR 100.11 ... an applicant should assume a fission produce release ${ }^{l}$ from the core, the expected demonstrable leak rate from the containment 
${ }^{1}$ The fission product release assumed for these calculations should be based upon a major accident, hypothesized for purposes of site analysis or postulated from considerations of possible accidental events, that would result in potential hazards not exceeded by those from any accident considered credible. Such accidents have generally been assumed to result in substantial meltdown of the core with subsequent release of appreciable quantities of fission products.

The core of an MSR is molten during normal operations. Moreover, fission products are released from the core of MSRs as part of normal operations, as the fuel salt is not intended to contain all of the fission products. The bulk of the releasable fission products will be in the cover gas handling system. A major rupture of the fuel salt first boundary layer might be an appropriate analogy for MSRs.

10 CFR 50.34 (D) (4) ... Analysis and evaluation of [emergency core cooling system] ECCS cooling performance and the need for high point vents following postulated lossof-coolant accidents must be performed in accordance with the requirements of $\$ 50.46$ and $\$ 50.46 a$.

10 CFR 50.46 "Acceptance criteria for emergency core cooling systems for light-water nuclear power reactors" and 10 CFR 50.46a "Acceptance criteria for reactor coolant system venting systems" both only pertain to LWRs, yet 10 CFR 50.34 (D) (4) requires their use for all applicants. MSRs are unlikely to employ ECCSs, and high-point vents would provide a potential breach path of the first low-leakage containment layer.

10 CFR 50.34 (b) (6) (vii) (9) A description of protection provided against pressurized thermal shock events, including projected values of the reference temperature for reactor vessel beltline materials as defined in $\$ 50.61$ (b)(1) and (b)(2).

Pressurized thermal shock is only pertinent to PWRs, as noted in 10 CFR 50.61 (a) (2), yet 10 CFR 50.34 (b) (6) (vii) (9) requires consideration for all applicants.

10 CFR 50.36(c)(1)(B)(ii)(B)(2)(ii) (A) Criterion 1. Installed instrumentation that is used to detect, and indicate in the control room, a significant abnormal degradation of the reactor coolant pressure boundary.

MSRs lack a pressure boundary, and the minimally radioactive material across the primary heat exchanger is frequently referred to as the coolant. The safety intent of the language would appear to most analogously refer to the innermost layer of low-leakage radionuclide containment at MSRs, which would include both the fuel salt circuit and the highly radioactive portion of the cover gas containment system. However, failure of an LWR's coolant pressure boundary is central to a failure cascade leading to large quantity radionuclide release to the environment. No single element of an MSR's containment layers has as great a safety significance as an LWR's primary coolant pressure boundary.

10 CFR 50.68 Criticality accident requirements.

(1) Plant procedures shall prohibit the handling and storage at any one time of more fuel assemblies than have been determined to be safely subcritical under the most adverse moderation conditions feasible by unborated water.

MSR fuel handling specifications must be based upon the fuel salt container employed at the individual plant. 
The 10 CFR Part 50, Appendix A criteria will require adaption for liquid fuel. A guidance document providing partial step towards MSR focused rules has already been issued. ARDC are provided in RG 1.232. However, the ARDC will require substantial adaption and interpretation for liquid fuel. RG 1.232 includes class-specific criteria for sodium fast reactors and modular high-temperature gas reactors, but it does not include MSR class specific criteria.

The American Nuclear Society working group on Nuclear Safety Design Criteria and Functional Performance Requirements for Liquid Fuel Molten-Salt Reactor Nuclear Power Plants is attempting to develop MSR class specific design criteria. Once completed, NRC staff should consider endorsing the ANS 20.2 MSR-specific design criteria.

Additional examples of potential confusion and additional complexity of liquid vs. solid fuel ARDC compliance are shown in Table A.1.

Table A.1. Examples of Conflicting Guidance for Liquid vs. Solid Fuels.

\begin{tabular}{|c|c|c|}
\hline $\begin{array}{c}\text { ARDC number } \\
\text { and title }\end{array}$ & ARDC content & Liquid fuel complexity \\
\hline 10. Reactor Design & $\begin{array}{l}\text { The reactor core and associated coolant, control, } \\
\text { and protection systems shall be designed with } \\
\text { appropriate margin to assure that specified } \\
\text { acceptable fuel design limits are not exceeded } \\
\text { during any condition of normal operation, } \\
\text { including the effects of anticipated operational } \\
\text { occurrences. }\end{array}$ & $\begin{array}{l}\text { Radionuclide release design limits } \\
\text { may be more appropriate for liquid- } \\
\text { fueled reactors than specified } \\
\text { acceptable fuel design limits. }\end{array}$ \\
\hline $\begin{array}{l}\text { 14. Reactor Coolant } \\
\text { Boundary }\end{array}$ & $\begin{array}{l}\text { The reactor coolant boundary shall be designed, } \\
\text { fabricated, erected, and tested so as to have an } \\
\text { extremely low probability of abnormal leakage, of } \\
\text { rapidly propagating failure, and of gross rupture. }\end{array}$ & $\begin{array}{l}\text { In MSRs, a layer other than the fuel } \\
\text { circuit boundary could provide the } \\
\text { safety function. The fuel circuit } \\
\text { boundary is only one layer within an } \\
\text { MSR's radionuclide containment } \\
\text { system. SRM-SECY-18-0096 } \\
\text { (Functional Containment) allows } \\
\text { individual layer failure provided } \\
\text { safety function is maintained. }\end{array}$ \\
\hline 28. Reactivity Limits & $\begin{array}{l}\text { The reactivity control systems shall be designed } \\
\text { with appropriate limits on the potential amount } \\
\text { and rate of reactivity increase to ensure that the } \\
\text { effects of postulated reactivity accidents can } \\
\text { neither (1) result in damage to the reactor coolant } \\
\text { boundary greater than limited local yielding nor } \\
\text { (2) sufficiently disturb the core, its support } \\
\text { structures, or other reactor vessel internals to } \\
\text { impair significantly the capability to cool the core. }\end{array}$ & $\begin{array}{l}\text { Parts of an MSR's fuel circuit are } \\
\text { outside of the core and perhaps the } \\
\text { vessel. Fuel system cooling } \\
\text { capability must not be significantly } \\
\text { impaired by damage to these external } \\
\text { components. }\end{array}$ \\
\hline $\begin{array}{l}30 \text { Quality of Reactor } \\
\text { Coolant Boundary }\end{array}$ & $\begin{array}{l}\text { Components that are part of the reactor coolant } \\
\text { boundary shall be designed, fabricated, erected, } \\
\text { and tested to the highest quality standards } \\
\text { practical. Means shall be provided for detecting } \\
\text { and, to the extent practical, identifying the } \\
\text { location of the source of reactor coolant leakage. }\end{array}$ & $\begin{array}{l}\text { In MSRs, a layer other than the fuel } \\
\text { circuit boundary could provide the } \\
\text { safety function. The fuel circuit } \\
\text { boundary is only one layer within an } \\
\text { MSR's radionuclide containment } \\
\text { system. SRM-SECY-18-0096 } \\
\text { (Functional Containment) allows } \\
\text { layer failure provided safety function } \\
\text { is maintained. }\end{array}$ \\
\hline
\end{tabular}


Table A.2. Examples of Conflicting Guidance for Liquid vs. Solid Fuels (continued).

\begin{tabular}{|c|c|c|}
\hline $\begin{array}{l}\text { ARDC number } \\
\text { and title }\end{array}$ & ARDC content & Liquid fuel complexity \\
\hline $\begin{array}{l}31 \text { Fracture prevention } \\
\text { of reactor coolant } \\
\text { boundary }\end{array}$ & $\begin{array}{l}\text { The reactor coolant boundary shall be designed } \\
\text { with sufficient margin to ensure that when } \\
\text { stressed under operating, maintenance, testing, } \\
\text { and postulated accident conditions, (1) the } \\
\text { boundary behaves in a nonbrittle manner and } \\
\text { (2) the probability of rapidly propagating fracture } \\
\text { is minimized. The design shall reflect } \\
\text { consideration of service temperatures, service } \\
\text { degradation of material properties, creep, fatigue, } \\
\text { stress rupture, and other conditions of the } \\
\text { boundary material under operating, maintenance, } \\
\text { testing, and postulated accident conditions and the } \\
\text { uncertainties in determining (1) material } \\
\text { properties, (2) the effects of irradiation and } \\
\text { coolant composition, including contaminants and } \\
\text { reaction products, on material properties, } \\
\text { (3) residual, steady-state, and transient stresses, } \\
\text { and (4) size of flaws. }\end{array}$ & $\begin{array}{l}\text { In MSRs, a layer other than the fuel } \\
\text { circuit boundary could provide the } \\
\text { safety function. The fuel circuit } \\
\text { boundary is only one layer within an } \\
\text { MSR's radionuclide containment } \\
\text { system. SRM-SECY-18-0096 } \\
\text { (Functional Containment) allows } \\
\text { layer failure provided safety function } \\
\text { is maintained. }\end{array}$ \\
\hline $\begin{array}{l}32 \text { Inspection of reactor } \\
\text { coolant boundary }\end{array}$ & $\begin{array}{l}\text { Components that are part of the reactor coolant } \\
\text { boundary shall be designed to permit (1) periodic } \\
\text { inspection and functional testing of important } \\
\text { areas and features to assess their structural and } \\
\text { leaktight integrity, and (2) an appropriate material } \\
\text { surveillance program for the reactor vessel. }\end{array}$ & $\begin{array}{l}\text { In MSRs, a layer other than the fuel } \\
\text { circuit boundary could provide the } \\
\text { safety function. The fuel circuit } \\
\text { boundary is only one layer within an } \\
\text { MSR's radionuclide containment } \\
\text { system. SRM-SECY-18-0096 } \\
\text { (Functional Containment) allows } \\
\text { layer failure provided safety function } \\
\text { is maintained. }\end{array}$ \\
\hline $\begin{array}{l}33 \text { Reactor coolant } \\
\text { inventory maintenance }\end{array}$ & $\begin{array}{l}\text { A system to maintain reactor coolant inventory for } \\
\text { protection against small breaks in the reactor } \\
\text { coolant boundary shall be provided as necessary } \\
\text { to ensure that specified acceptable fuel design } \\
\text { limits are not exceeded as a result of reactor } \\
\text { coolant inventory loss due to leakage from the } \\
\text { reactor coolant boundary and rupture of small } \\
\text { piping or other small components that are part of } \\
\text { the boundary. The system shall be designed to } \\
\text { ensure that the system safety function can be } \\
\text { accomplished using the piping, pumps, and valves } \\
\text { used to maintain reactor coolant inventory during } \\
\text { normal reactor operation. }\end{array}$ & $\begin{array}{l}\text { The reactor coolant is also the fuel. It } \\
\text { may be inadvisable to add fuel to the } \\
\text { reactor during accidents. }\end{array}$ \\
\hline $\begin{array}{l}34 \text { Residual Heat } \\
\text { Removal }\end{array}$ & $\begin{array}{l}\text { A system to remove residual heat shall be } \\
\text { provided. For normal operations and anticipated } \\
\text { operational occurrences, the system safety } \\
\text { function shall be to transfer fission product decay } \\
\text { heat and other residual heat from the reactor core } \\
\text { at a rate such that specified acceptable fuel design } \\
\text { limits and the design conditions of the reactor } \\
\text { coolant boundary are not exceeded. } \\
\text { Suitable redundancy in components and features } \\
\text { and suitable interconnections, leak detection, and } \\
\text { isolation capabilities shall be provided to ensure }\end{array}$ & $\begin{array}{l}\text { SARRDLs would be more } \\
\text { appropriate for MSRs. In MSRs, a } \\
\text { layer other than the fuel circuit } \\
\text { boundary could provide the safety } \\
\text { function. The fuel circuit boundary is } \\
\text { only one layer within an MSR's } \\
\text { radionuclide containment system. } \\
\text { SRM-SECY-18-0096 (Functional } \\
\text { Containment) allows layer failure } \\
\text { provided safety function is } \\
\text { maintained. }\end{array}$ \\
\hline
\end{tabular}


Table A.2. Examples of Conflicting Guidance for Liquid vs. Solid Fuels (continued).

\begin{tabular}{|c|c|c|}
\hline $\begin{array}{l}\text { ARDC number } \\
\text { and title }\end{array}$ & ARDC content & Liquid fuel complexity \\
\hline & $\begin{array}{l}\text { that the system safety function can be } \\
\text { accomplished, assuming a single failure. }\end{array}$ & \\
\hline $\begin{array}{l}\text { 35. Emergency Core } \\
\text { Cooling System }\end{array}$ & $\begin{array}{l}\text { A system to assure sufficient core cooling during } \\
\text { postulated accidents and to remove residual heat } \\
\text { following postulated accidents shall be provided. } \\
\text { The system safety function shall be to transfer } \\
\text { heat from the reactor core during and following } \\
\text { postulated accidents such that fuel and clad } \\
\text { damage that could interfere with continued } \\
\text { effective core cooling is prevented. }\end{array}$ & $\begin{array}{l}\text { The term fuel and clad damage is } \\
\text { confusing when referencing liquid } \\
\text { fuel systems since liquid fuel has no } \\
\text { cladding and cannot be damaged in } \\
\text { the same manner as solid fuel. Also, } \\
\text { heat needs to be removed from all of } \\
\text { the MSR's fuel salt circuit and cover } \\
\text { gas handling system, not just the } \\
\text { portion in the core. }\end{array}$ \\
\hline $\begin{array}{l}\text { 36. Inspection of } \\
\text { Emergency Core } \\
\text { Cooling System }\end{array}$ & $\begin{array}{l}\text { A system that provides emergency core cooling } \\
\text { shall be designed to permit appropriate periodic } \\
\text { inspection of important components to ensure the } \\
\text { integrity and capability of the system. }\end{array}$ & $\begin{array}{l}\text { All of the MSR's fuel salt within the } \\
\text { fuel salt circuit, not just the portion } \\
\text { of the fuel salt that is critical, and the } \\
\text { cover gas handling system would } \\
\text { require cooling during accident } \\
\text { conditions. }\end{array}$ \\
\hline $\begin{array}{l}\text { 37. Testing of } \\
\text { Emergency Core } \\
\text { Cooling System }\end{array}$ & $\begin{array}{l}\text { A system that provides emergency core cooling } \\
\text { shall be designed to permit appropriate periodic } \\
\text { functional testing to ensure (1) the structural and } \\
\text { leaktight integrity of its components, (2) the } \\
\text { operability and performance of the system } \\
\text { components, and (3) the operability of the system } \\
\text { as a whole and, under conditions as close to } \\
\text { design as practical, the performance of the full } \\
\text { operational sequence that brings the system into } \\
\text { operation, including operation of any associated } \\
\text { systems and interfaces necessary to transfer decay } \\
\text { heat to the ultimate heat sink. }\end{array}$ & $\begin{array}{l}\text { All of the MSR's fuel salt within the } \\
\text { fuel salt circuit, not just the portion } \\
\text { of the fuel salt that is critical, and } \\
\text { cover gas handling system would } \\
\text { require cooling during accident } \\
\text { conditions. }\end{array}$ \\
\hline $\begin{array}{l}\text { 51. Fracture Prevention } \\
\text { of Containment } \\
\text { Pressure Boundary }\end{array}$ & $\begin{array}{l}\text { The boundary of the containment structure shall } \\
\text { be designed with sufficient margin to ensure that, } \\
\text { under operating, maintenance, testing, and } \\
\text { postulated accident conditions, (1) its materials } \\
\text { behave in a nonbrittle manner and (2) the } \\
\text { probability of rapidly propagating fracture is } \\
\text { minimized. The design shall reflect consideration } \\
\text { of service temperatures and other conditions of } \\
\text { the containment boundary materials during } \\
\text { operation, maintenance, testing, and postulated } \\
\text { accident conditions, and the uncertainties in } \\
\text { determining (1) material properties, (2) residual, } \\
\text { steady-state, and transient stresses, and (3) size of } \\
\text { flaws. }\end{array}$ & $\begin{array}{l}\text { The first layer of containment is also } \\
\text { the fuel system boundary. SRM- } \\
\text { SECY-18-0096 (Functional } \\
\text { Containment) allows layer failure } \\
\text { provided overall safety function is } \\
\text { maintained. Unclear whether the } \\
\text { materials of individual layers may be } \\
\text { permitted to behave in a brittle } \\
\text { manner. More hot systems also } \\
\text { require cooling. }\end{array}$ \\
\hline $\begin{array}{l}\text { 55. Reactor Coolant } \\
\text { Boundary Penetrating } \\
\text { Containment }\end{array}$ & $\begin{array}{l}\text { Each line that is part of the reactor coolant } \\
\text { boundary and that penetrates the containment } \\
\text { structure shall be provided with containment } \\
\text { isolation valves, as follows, unless it can be } \\
\text { demonstrated that the containment isolation } \\
\text { provisions for a specific class of lines, such as }\end{array}$ & $\begin{array}{l}\text { Clarification is needed to specify that } \\
\text { the coolant system referred to is the } \\
\text { nonfueled coolant salt coupled to the } \\
\text { fuel salt within containment. }\end{array}$ \\
\hline
\end{tabular}


Table A.2. Examples of Conflicting Guidance for Liquid vs. Solid Fuels (continued).

\begin{tabular}{|l|l|l|}
\hline \multicolumn{1}{|c|}{$\begin{array}{c}\text { ARDC number } \\
\text { and title }\end{array}$} & \multicolumn{1}{|c|}{ ARDC content } & Liquid fuel complexity \\
\hline & $\begin{array}{l}\text { instrument lines, are acceptable on some other } \\
\text { defined basis: } \\
\text { (1) One locked closed isolation valve inside and } \\
\text { one locked closed isolation valve outside } \\
\text { containment; or } \\
\text { (2) One automatic isolation valve inside and one } \\
\text { locked closed isolation valve outside containment; } \\
\text { or } \\
\text { (3) One locked closed isolation valve inside and } \\
\text { one automatic isolation valve outside } \\
\text { containment. A simple check valve may not be } \\
\text { used as the automatic isolation valve outside } \\
\text { containment; or } \\
\text { (4) One automatic isolation valve inside and one } \\
\text { automatic isolation valve outside containment. A } \\
\text { simple check valve may not be used as the } \\
\text { automatic isolation valve outside containment. } \\
\text { Isolation valves outside containment shall be } \\
\text { located as close to containment as practical and } \\
\text { upon loss of actuating power, automatic isolation } \\
\text { valves shall be designed to take the position that } \\
\text { provides greater safety. } \\
\text { Other appropriate requirements to minimize the } \\
\text { probability or consequences of an accidental } \\
\text { rupture of these lines or of lines connected to } \\
\text { them shall be provided as necessary to ensure } \\
\text { adequate safety. Determination of the } \\
\text { appropriateness of these requirements, such as } \\
\text { higher quality in design, fabrication, and testing; } \\
\text { additional provisions for inservice inspection; } \\
\text { protection against more severe natural } \\
\text { phenomena; and additional isolation valves and } \\
\text { containment, shall include consideration of the } \\
\text { population density, use characteristics, and } \\
\text { physical characteristics of the site environs. }\end{array}$ & \\
& & \\
\hline
\end{tabular}

